\title{
Genome-wide characterization, expression analyses, and functional prediction of the NPF family in Brassica napus
}

Jing Wen ${ }^{1,2 \dagger}$, Peng-Feng Li $i^{1,2 \dagger}$, Feng Ran ${ }^{1,2}$, Peng-Cheng Guo ${ }^{1,2}$, Jia-Tian Zhu ${ }^{1,2}$, Jin Yang ${ }^{1,2}$, Lan-Lan Zhang ${ }^{1,2}$, Ping Chen ${ }^{1,2}$, Jia-Na $\mathrm{Li}^{1,2}$ and Hai Du ${ }^{1,2^{*}}$ (D)

\begin{abstract}
Background: NITRATE TRANSPORTER 1/PEPTIDE TRANSPORTER (NRT1/PTR) family (NPF) members are essential transporters for many substrates in plants, including nitrate, hormones, peptides, and secondary metabolites. Here, we report the global characterization of NPF in the important oil crop Brassica napus, including that for phylogeny, gene/protein structures, duplications, and expression patterns.

Results: A total of 199 B. napus (BnaNPFs) NPF-coding genes were identified. Phylogenetic analyses categorized these genes into 11 subfamilies, including three new ones. Sequence feature analysis revealed that members of each subfamily contain conserved gene and protein structures. Many hormone-/abiotic stress-responsive cis-acting elements and transcription factor binding sites were identified in BnaNPF promoter regions. Chromosome distribution analysis indicated that BnaNPFs within a subfamily tend to cluster on one chromosome. Syntenic relationship analysis showed that allotetraploid creation by its ancestors (Brassica rapa and Brassica oleracea) (57.89\%) and small-scale duplication events (39.85\%) contributed to rapid BnaNPF expansion in B. napus. A genome-wide spatiotemporal expression survey showed that NPF genes of each Arabidopsis and B. napus subfamily have preferential expression patterns across developmental stages, most of them are expressed in a few organs. RNA-seq analysis showed that many BnaNPFs (32.66\%) have wide exogenous hormone-inductive profiles, suggesting important hormone-mediated patterns in diverse bioprocesses. Homologs in a clade or branch within a given subfamily have conserved organ/ spatiotemporal and hormone-inductive profiles, indicating functional conservation during evolution. qRT-PCR-based comparative expression analysis of the 12 BnaNPFs in the NPF2-1 subfamily between high- and low-glucosinolate (GLS) content B. napus varieties revealed that homologs of AtNPF2.9 (BnaNPF2.12, BnaNPF2.13, and BnaNPF2.14), AtNPF2.10 (BnaNPF2.19 and BnaNPF2.20), and AtNPF2.11 (BnaNPF2.26 and BnaNPF2.28) might be involved in GLS transport. QRT-PCR further confirmed the hormone-responsive expression profiles of these putative GLS transporter genes.

(Continued on next page)
\end{abstract}

\footnotetext{
* Correspondence: haidu81@126.com; dh20130904@swu.edu.cn

†'Jing Wen and Peng-Feng Li contributed equally to this work.

'College of Agronomy and Biotechnology, Chongqing Engineering Research

Center for Rapeseed, Southwest University, Chongqing 400716, China

${ }^{2}$ Academy of Agricultural Sciences, Southwest University, Chongqing 400716,

China
}

(c) The Author(s). 2020 Open Access This article is licensed under a Creative Commons Attribution 4.0 International License, which permits use, sharing, adaptation, distribution and reproduction in any medium or format, as long as you give appropriate credit to the original author(s) and the source, provide a link to the Creative Commons licence, and indicate if changes were made. The images or other third party material in this article are included in the article's Creative Commons licence, unless indicated otherwise in a credit line to the material. If material is not included in the article's Creative Commons licence and your intended use is not permitted by statutory regulation or exceeds the permitted use, you will need to obtain permission directly from the copyright holder. To view a copy of this licence, visit http://creativecommons.org/licenses/by/4.0/ The Creative Commons Public Domain Dedication waiver (http://creativecommons.org/publicdomain/zero/1.0/) applies to the data made available in this article, unless otherwise stated in a credit line to the data. 
(Continued from previous page)

Conclusion: We identified 199 B. napus BnaNPFs; these were divided into 11 subfamilies. Allopolyploidy and small-scale duplication events contributed to the immense expansion of BnaNPFs in B. napus. The BnaNPFs had preferential expression patterns in different tissues/organs and wide hormone-induced expression profiles. Four BnaNPFs in the NPF2-1 subfamily may be involved in GLS transport. Our results provide an abundant gene resource for further functional analysis of BnaNPFs.

Keywords: Brassica napus, NPF, Expression analysis, Hormone, Glucosinolate transporter

\section{Background}

NITRATE TRANSPORTER 1/PEPTIDE TRANSPORTER (NRT1/PTR) homologous proteins are a group of membrane transport proteins present in all major living kingdoms [1-5]. Generally, 12 transmembrane domain (TM) proteins have a conserved structural arrangement connected by short peptide loops, including a large hydrophilic loop between the sixth and seventh TM [5]. In previous studies, homologous proteins were conventionally named according to their first identified substrates, such as NRT (a nitrate transporter), PTR (a peptide transporter), and others $[1,6]$. Thereafter, additional substrates of NRT1/PTR homologs were characterized in plants; thus, they were recently and uniformly named as members of the NRT1/PTR family (NPF) [7].

Since AtNPF6.3/AtNRT1.1/CHL1 is characterized as a dual-affinity nitrate transporter in Arabidopsis [6, 8, 9], many of its homologs are cloned and functionally characterized in many plant species with multisubstrate transporting capacity. To date, the most well known roles of plant NPF genes (NPFs) include low- and/or high-affinity nitrate transportation. For example, Arabidopsis AtNPF1.1/NRT1.11 and AtNPF1.2/NRT1.12 proteins are low-affinity nitrate transporters involved in redistributing nitrate into developing leaves [10], while Zea mays (maize) ZmNPF6.6 is a high-affinity nitrate transporter that can rapidly respond to exogenous nitrate supply [11]. Meanwhile, NPF proteins (NPFs) also behave as nitrite transporters, e.g., Arabidopsis AtNPF3.1/Nitr and Vitis vinifera VvNPF3.2 [12]. Additionally, NPFs are key transporters for many other substrates, especially hormones and peptides. For example, AtNPF8.1/PTR1 [13, 14], AtNPF8.2/ PTR5 [14], and AtNPF8.3/PTR2 [15, 16] are di-/tri-peptide transporters that can mediate the process of flowering, as well as seed and root development; AtNPF4.6/ AIT1 transports abscisic acid (ABA) to regulate stomatal aperture [17, 18]; and AtNPF6.3 represses lateral root growth during low nitrate availability by promoting basipetal auxin (IAA) transport [19]. Moreover, members of NPF have been demonstrated to transport secondary metabolites; AtNPF2.10/GTR1 and AtNPF2.11/GTR2 are key transporters for glucosinolate (GLS) [20]. Additionally, a few NPFs display chloride or potassium transport activity: AtNPF2.4 and AtNPF2.5 mediate chloride efflux activity
$[21,22]$, while AtNPF7.3/NRT1.5 regulates pH-dependent $\mathrm{K}^{+}$efflux activity [23].

Brassica napus is a significant source of human-edible vegetable oil and animal protein feed; thus, it is an essential oil crop, extensively cultivated in Asia, North America, and Europe. Given essential roles in plant nitrate, di-/tripeptide, hormone, potassium, chloride, and secondary metabolite transports, NPFs have been systematically identified and analyzed in many species, including Arabidopsis [20], Oryza sativa (rice) [24], Triticum aestivum (wheat) [25], and Malus domestica (apple) [26] at the genome-wide level. Identifying and analyzing this gene family in the $B$. napus genome will provide a solid foundation for exploring its potential roles in transporting nitrate, hormones, and GLS, among others.

This study identified NPFs in the B. napus genome, accompanied by comprehensive analysis of their gene and protein structural features, chromosomal location, classification, promoter regulation network, and genomic duplication mechanism. Further, we performed systematic expression profile analysis of this gene family in diverse tissues across different developmental stages in Arabidopsis (79 tissues) and B. napus (50 tissues). Additionally, expression patterns of NPF gene family in $B$. napus under five exogenous hormone inductions (IAA, auxin; ABA, abscisic acid; $\mathrm{GA}_{3}$, gibberellic acid; 6-BA, cytokinin; and ACC, ethylene) were assessed, based on the RNA-Seq dataset. Moreover, expression patterns of 12 candidate NPFs of the NPF2-1 subfamily in one high- and one low-GLS B. napus variety, as well as their expression profiles under hormone induction, were assessed using qRT-PCR. Our study provides an abundant gene resource for further functional analysis of NPFs in B. napus.

\section{Results}

\section{Identification and phylogenetic analysis of NPF proteins} in B. napus

In total, 199 nonredundant NPF protein sequences were obtained in B. napus Darmor-bzh genome (BnaNPFs) by BLASTP search of the GENOSCOPE dataset (http://www. genoscope.cns.fr/brassicanapus/) [27] and subsequent confirmation by SMART (http://pfam.xfam.org/search/sequence) [28] and PFAM (http://smart.embl-heidelberg.de/ smart/show_motifs.pl) [29] analyses (Additional file 1: 
Table S1). Naming of the candidate BnaNPFs was consistent with previously reported rules [7]. The length of the 199 candidate BnaNPFs ranged from 100 aa (BnaNPF1.4) to 1547 aa (BnaNPF1.9), and the molecular weight ranged from 11.57 kDa (BnaNPF1.4) to $171.42 \mathrm{kDa}$ (BnaNPF1.9). The isoelectric point (pI) ranged from 4.71 (BnaNPF8.13) to 10.23 (BnaNPF2.42), where 40 members had pI values $<7$, and 159 members had pI values $>7$, suggesting that most of these genes encode alkaline proteins. Subcellular localization prediction by Cell-PLoc2.0 (http://www.csbio. sjtu.edu.cn/bioinf/Cell-PLoc-2/) [30], Pprowler (http:// bioinf.scmb.uq.edu.au:8080/pprowler_webapp_1-2/index. jsp) [31], and WoLF PSORT (https://wolfpsort.hgc.jp/) [32] analysis showed that results from these three software tools were highly consistent, and that almost all BnaNPFs are located on the plasmalemma or vacuole (Additional file 1: Table S1). In addition, 100 nonredundant NPF protein sequences were identified in the Brassica oleracea genome (BolNPFs) in the BRAD database (http:// brassicadb.org/brad/) [33] by the same method (Additional file 2: Table S2). The 53 NPF protein sequences in Arabidopsis (AtNPFs) and $94 \mathrm{NPF}$ protein sequences in Brassica rapa (BraNPFs) were obtained from a previous study [7] (Additional file 2: Table S2).

To explore the classification and evolution of candidate BnaNPFs, multiple sequences of the 53 AtNPFs and the 199 BnaNPFs were aligned using the MAFFT software (https://mafft.cbrc.jp/alignment/server/) [34]. Then, a neighbor-joining (NJ) and maximum-likelihood (ML) phylogenetic tree, were constructed using MEGA 7.0 [35], based on the multiple sequence alignment. Notably, 44 BnaNPFs with large $\mathrm{C}$ - or N-terminal deletions were removed from construction of a phylogenetic tree due to lack of common sequence sites; the phylogenetic relationship and classification of these BnaNPFs were predicted by sequence similarity with AtNPFs instead (Additional file 1: Table S1). Based on the topologies and bootstrap support values of the NJ phylogenetic tree, candidate NPFs were divided into 11 subfamilies (Fig. 1). A previous study including 33 plant species divided the NPF family into eight subfamilies (NPF1-NPF8) [7]; three of the eight previously classified subfamilies (NPF2, NPF5, and NPF6 subfamilies) were further divided into two subfamilies in our NJ tree (Fig. 1). Moreover, the results of the NJ and ML trees constructed in this study were highly consistent (Fig. 1 and Additional file 3: Figure S1), demonstrating the reliability of our classification. The distribution of BnaNPFs among different subfamilies was as follows: NPF1 (11), NPF2-1 (36), NPF2-2 (7), NPF3 (7), NPF4 (20), NPF5-1 (71), NPF5-2 (2), NPF6-1 (11), NPF6-2 (2), NPF7 (10), and NPF8 (22). The difference in the number of BnaNPFs in the 11 subfamilies indicated a distinct expansion trend among these subfamilies.

\section{Protein characteristics and intron pattern diversity}

Based on multiple alignment analysis of the 155 fulllength BnaNPFs with relatively complete coding regions, the protein sequence feature was further explored. TMs and other conserved protein domains were predicted using the HMMER software (http://www.ebi.ac.uk/Tools/ hmmer) [36].

Protein sequence analysis showed that all BnaNPFs contained the PTR2 domain responsible for proton-dependent transport. Moreover, 82.58\% (128/155) of BnaNPFs contained 10-12 TMs, $15.48 \%$ (24/155) of BnaNPFs had 6-9 TMs, and $0.02 \%(3 / 155)$ of BnaNPFs had 13 TMs. In general, distribution of TMs was conserved in each clade within a subfamily, suggesting functional conservation (Additional file 4: Figure S2). Consistent with a previous report [37], the conserved $E_{1} X_{1} X_{2} E_{2} R(K)$ motif was found at the $N$ terminus of the first TM in 8 of the 11 subfamilies (Additional file 5: Figure S3), though not in S7, S2-2, or S5-2.

At the nucleic acid sequence level, we further analyzed the intron insertion site, number, and phase of candidate BnaNPFs by using the Gene Structure Display Server (GSDS) 2.0 (http://gsds.gao-lab.org/) [38]. Our results showed that all 155 BnaNPFs contained 1-16 introns, and $86.45 \%(134 / 155)$ of BnaNPFs had 3-5 introns (Additional file 6: Figure S4). Notably, three of these introns were highly conserved in almost all BnaNPFs in terms of insertion sites and phases; one intron was inserted ahead of the PTR2 domain, and two introns were inserted within the PTR2 domain (one in the third TM and another between the sixth and seventh TMs) (Additional file 6: Figure S4). This finding suggests that these three introns may be necessary for the function of BnaNPFs. Moreover, apart from these three introns, the other introns were commonly conserved within each subfamily or clade, but were less conserved among distinct subfamilies (Additional file 6: Figure S4). Furthermore, we found that the intron insertion sites and phases of BnaNPFs and AtNPFs were highly conserved in each clade or subfamily (Additional file 6: Figure S4), indicating conserved structural features during their evolution.

Overall, the conserved protein and gene sequences strongly support our subfamily division based on phylogenetic analysis.

\section{Regulatory mechanism in the promoter regions of BnaNPFs}

Because cis-acting regulatory elements (CREs) in promoter regions are essential for regulating gene transcription levels [39], we predicted the CREs in the promoter regions (2000 bp) of BnaNPFs using PlantCARE (http://bioinformatics.psb.ugent.be/webtools/plantcare/html/) [40].

In total, 121 types of CREs were identified in the promoters of the 199 BnaNPFs, such as ABA-responsive ciselement (ABRE), heat stress-responsive cis-element (HSE), and HD-ZIP binding site (HD-Zip) (Fig. 2a; Additional file 7: 


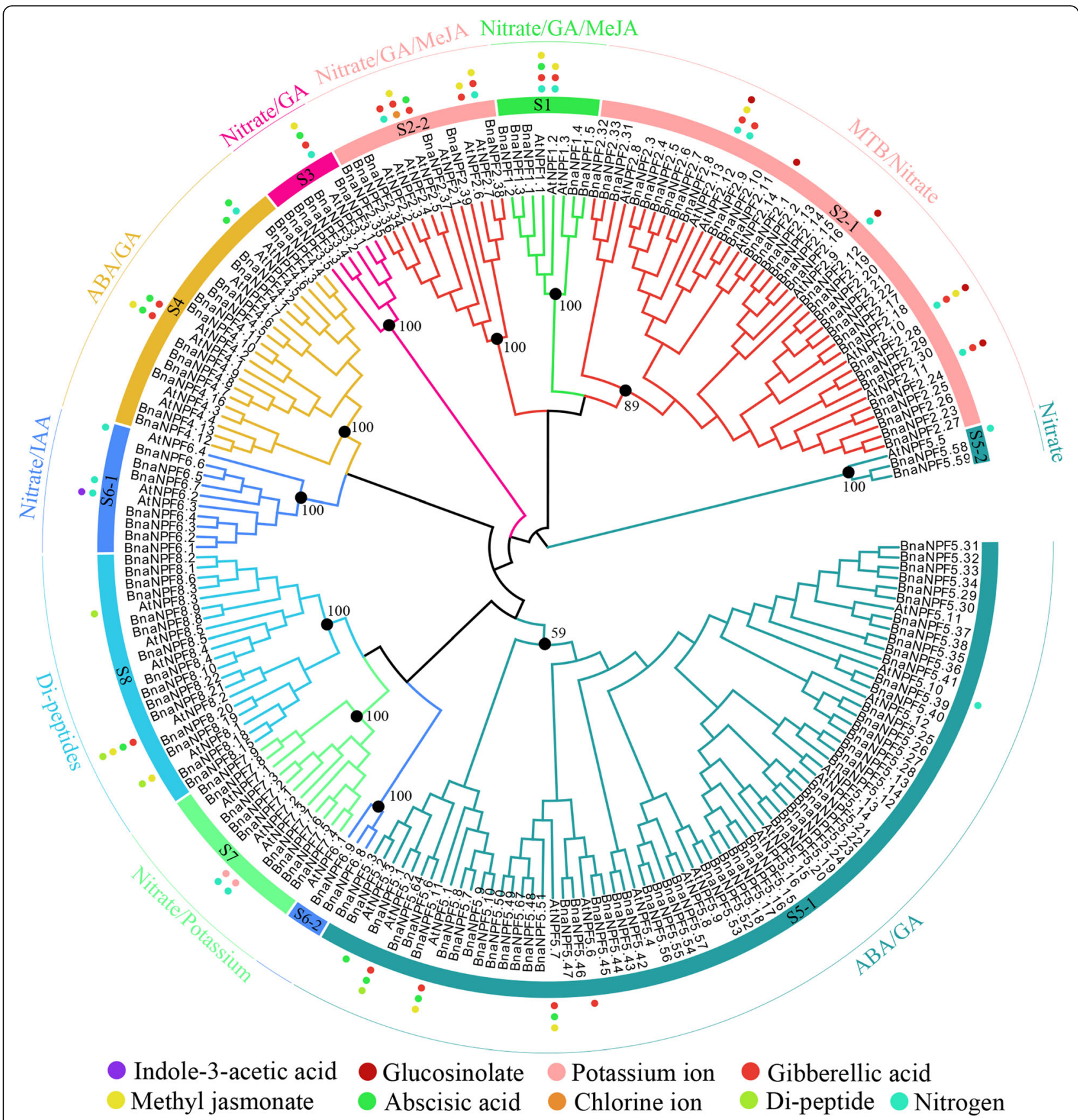

Fig. 1 Phylogenetic relationships of Brassica napus NPF proteins (BnaNPFs) and Arabidopsis NPF proteins (AtNPFs). The neighbor-joining tree (NJ) was built using the full-length NPF proteins in Arabidopsis (53) and B. napus (155); NPFs were classified into 11 subfamilies (S1, S2-1, S2-2, S3, S4, S5-1, S5-2, S6-1, S6-2, S7, and S8). The bootstrap value of each subfamily is marked in the tree with a black dot. The substrates of AtNPFs that had been functionally demonstrated are indicated in the subfamilies with colored dots, and the main substrates of each subfamily are summarized along the outer circle. IAA: indoleacetic acid, MeJA: methyl jasmonate, ABA: abscisic acid, GA: gibberellic acid, MTB: methylthiobutyl glucosinolate. The neighbor-joining tree was constructed by MEGA7.0 software and visualized and edited in Evolview V3

Table S3). In general, several common CREs, such as core elements (CAAT-box and TATA-box) and light-responsive cis-element (G-box), were obtained. Meanwhile, a mass of putative CREs that were involved in hormone responses, such as $\mathrm{GA}, \mathrm{ABA}$, and $\mathrm{ACC}$, were found in a series of BnaNPF promoters (Fig. 2a), suggesting that diverse hormone inductions may regulate their expression. Similarly, many putative $C R E \mathrm{~s}$ associated with abiotic stress, such as 


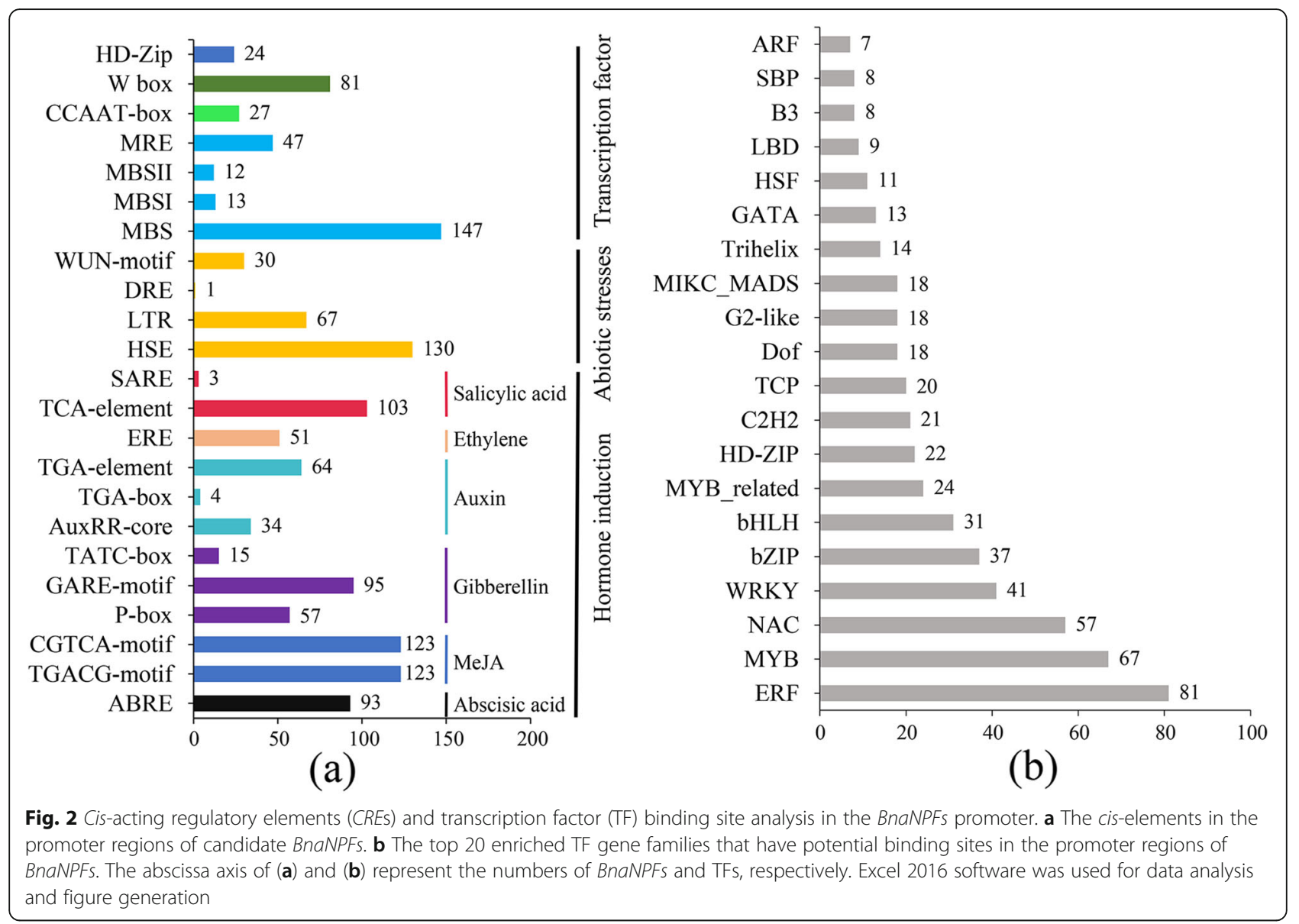

HSE (130 of 199 BnaNPFs), low temperature-responsive ciselement (LTR; 67 of 199 BnaNPFs), and wound-responsive cis-element (WUN-motif; 30 of 199 BnaNPFs), were identified in many BnaNPF promoters (Fig. 2a). Furthermore, many transcription factor (TF) binding sites were observed, such as myeloblastosis (MYB) binding sites (MRE, MBS, MBSI, and MBSII) and WRKY binding sites (W box), among others (Fig. 2a).

To further explore the regulatory mechanism of candidate BnaNPFs, we inferred the potential regulatory network of BnaNPFs using PlantTFDB (http://planttfdb.gao-lab.org/) (Fig. 2b) [41]. Our results showed that up to 582 TFs from 38 TF gene families had potential target binding sites in the promoter regions of BnaNPFs. The most enriched TFs belonged to MYB (92 of 582 genes), ethylene response element-binding factor (ERF, 81 genes), NAM-ATAF-CCUC domain-containing protein (NAC, 57 genes), WRKY DNAbinding protein (41 genes), basic leucine zipper (bZIP, 37 genes), and basic helix-loop-helix (bHLH, 31 genes) families (Fig. 2b and Additional file 8: Table S4).

In summary, our results reveal that expression of $B n a N P F s$ may be regulated by various kinds of hormones, abiotic stresses, and TFs.

\section{Chromosomal location and syntenic relationship in BnaNPFs}

The distribution of BnaNPFs on B. napus chromosomes was analyzed based on genomic annotation information obtained from the GENOSCOPE database (http://www. genoscope.cns.fr/brassicanapus/) [27]. As shown in Fig. 3a, most of the 199 BnaNPFs were mapped on the 19 chromosomes; however, the exact locations of 6 genes in $A_{n}$ subgenome and 29 genes in the $C_{n}$ subgenome were unclear (Additional file 1: Table S1). The numbers of BnaNPFs in $A_{n}$ (95) and $C_{n}$ (104) subgenomes were similar. However, the distribution of BnaNPFs on different chromosomes was uneven. For example, A03, A04, and C01 contained only three genes, while A07 had up to 22 genes (Fig. 3a). Notably, BnaNPFs belonging to the same subfamily tended to cluster on several chromosomes: $39.44 \%$ (28/71) of NPF5-1 subfamily members were distributed on the A02, A07, A09, and C02 chromosomes (Fig. 3a). Similar trends in the NPF gene family were observed in Arabidopsis, $B$. rapa, and $B$. oleracea. In Arabidopsis, all members of NPF2-2 subfamily (AtNPF2.1-AtNPF2.7) were clustered on the 03 chromosome, and $46.67 \%$ (7/15) of NPF5-1 


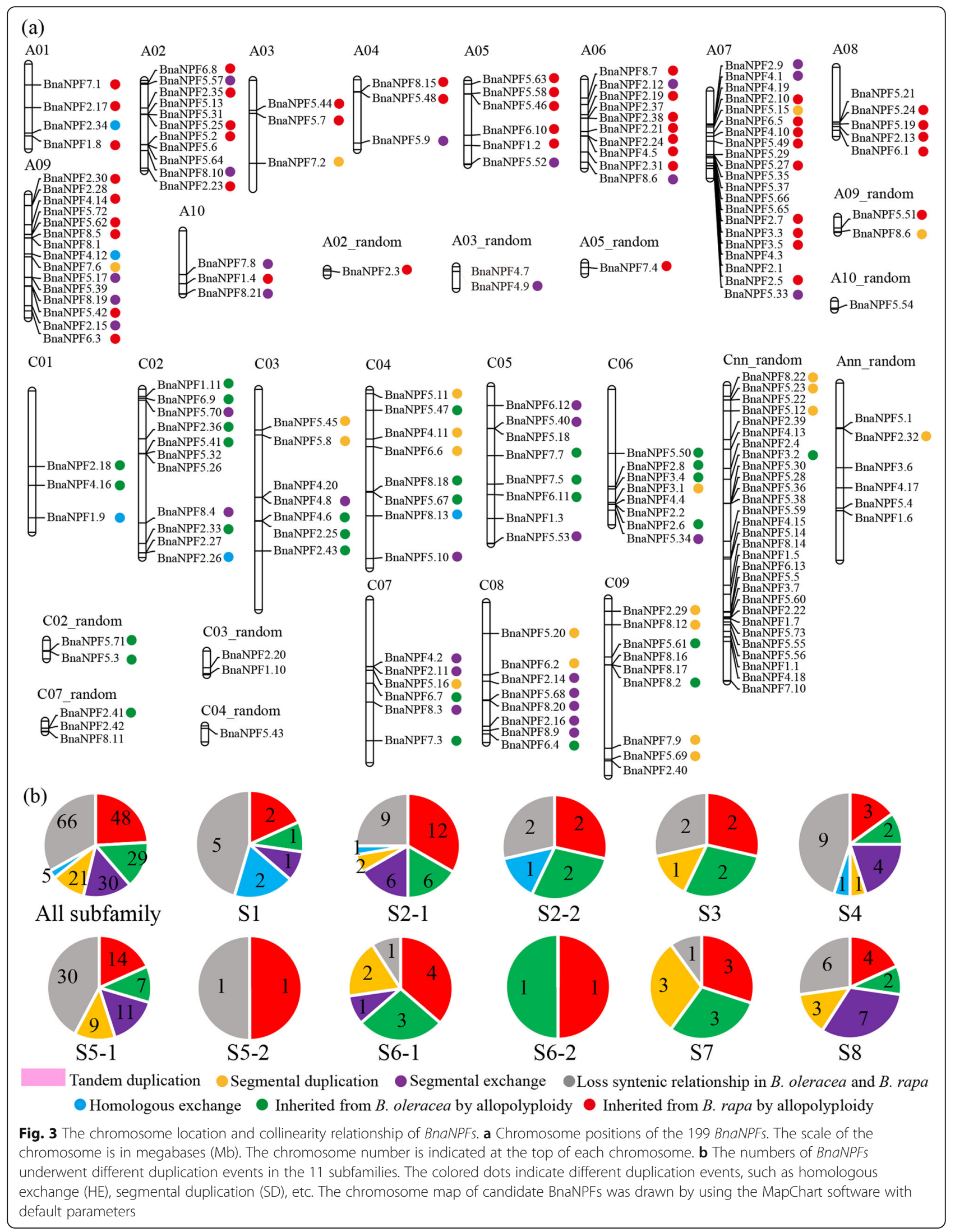


subfamily (AtNPF5.10-AtNPF5.16) members were clustered on the 01 chromosome (Additional file 9: Figure S5a); Similarly, members of NPF5-1 subfamily were distributed mainly on the A07 chromosome in B. rapa (Additional file 9: Figure S5b) and $\mathrm{C} 07$ chromosome in $B$. oleracea (Additional file 9: Figure S5c). These results suggest that NPFs in the same subfamily tend to assemble as gene clusters, and this trend may be conserved in plants.

The collinearity of NPFs in B. oleracea, B. rapa, and $B$. napus genomes was analyzed using the CoGe tool (https:/genomevolution.org/CoGe/) [42] to explore the expansion mechanism of BnaNPFs. Our results show that 133 of 199 BnaNPFs in the B. napus genome had a syntenic relationship (Fig. 3b; Additional file 10: Table S5). All 133 genes had a collinear relationship with BraNPFs, while 127 BnaNPFs had a collinear relationship with BolNPFs. We further speculated that 49 of the 133 genes (36.84\%) were inherited from B. rapa, and 28 genes (21.05\%) were inherited from the $B$. oleracea genome, based on the syntenic relationship between the descendant and its ancestors. Given that B. napus evolved by hybridization between $B$. oleracea and $B$. rapa $\sim 7500$ years ago, it was evident that allopolyploidy (57.89\%) heavily contributed to the rapid expansion of $N P F \mathrm{~s}$ in $B$. napus. Moreover, gene loss following allopolyploidy was biased; the NPFs inherited from B. rapa were inclined to be retained. Furthermore, 39.85\% (56/133) of genes originated from other duplication events within the $B$. napus genome, including 30 genes from segmental exchange (SE), 21 genes from segmental duplication (SD), and 5 genes from homologous exchange (HE) events. These results proved that small-scale duplication events (including $\mathrm{HE}, \mathrm{SE}$, and SD) also contributed to the massive expansion of NPFs in B. napus, especially the SE and SD events. Notably, of the 21 genes that underwent SD events, 15 were derived from B. rapa, while the remaining 6 were inherited from $B$. oleracea; this indicates that the genes from $B$. rapa tended to undergo SD in B. napus. Regarding the $\mathrm{HE}$ event, three of the five $\mathrm{HE}$ genes were from the $A_{n}$ subgenome, which replaced the genes in the $C_{n}$ subgenome. This finding confirmed that the $A_{n}$ subgenome replaced more of the $C_{n}$ subgenome after allopolyploidy and featured more dominantly in each chromosome [43]. Three pairs of putative tandem duplication (TD) genes (BnaNPF2.26/BnaNPF2.27, BnaNPF4.7/ BnaNPF4.9, and BnaNPF5.22/BnaNPF5.23) were observed, based on their chromosome distribution and sequence similarity.

Overall, our results indicate that allopolyploidy and small-scale duplication events (including SE, SD, and $\mathrm{HE}$ ) are the primary driving force for the rapid expansion of BnaNPFs in B. napus, and that those derived from $B$. rapa tended to be retained during evolution.

\section{Comparative expression analysis of AtNPFs and BnaNPFs across plant development}

As gene expression pattern is an essential clue as to its function, in order to explore gene expression patterns as well as expression and function similarity between different species, we analyzed and compared global expression profiles of AtNPFs and BnaNPFs in different tissues and organs at distinct developmental stages. We used public expression datasets of Arabidopsis (http://bar.utoronto. ca/efp/cgi-bin/efpWeb.cgi) [44] and B. napus (BioProject ID PRJNA358784).

In $B$. napus, with the exception of 67 BnaNPFs having no detectable expression values $(\mathrm{FPKM}<1)$ that were excluded from analysis (Additional file 11: Table S6), most $(132 / 199)$ of the remaining genes had preferential expression profiles in the 50 tissues of seven organs (root, stem, leaf, hypocotyl, flower, silique pericarp, and seed) at six developmental stages (Fig. 4 and Additional file 11: Table S6). For instance, members of the NPF1 subfamily had higher transcriptional levels in root, stem, hypocotyl, flower, and silique pericarp; members of NPF7 were highly expressed in flowers, silique pericarp, and seeds; and members of NPF2-1 were mainly expressed in flower and seed tissues (Fig. 4). In general, expression patterns were conserved in each subfamily or each clade within a subfamily, but were quite different across different subfamilies, suggesting the expression differentiation trend of this gene family. For example, expression patterns of NPF1, NPF2-2, NPF3, and NPF6-1 subfamilies were similar in each subfamily, while the expression profile of the NPF2-1 subfamily was classified into three conserved patterns that were consistent with the three major clades in this subfamily. Additionally, we found that $40 \%(6 / 15)$ of the $B n a N P F s$ expressed explicitly in seeds belong to the NPF2-1 subfamily, and 33.33\% (5/15) belong to the NPF4 subfamily, suggesting essential roles for these two subfamilies in seed development.

In Arabidopsis, consistent with the situation in $B$. napus, most of the AtNPFs had preferential expression patterns in the organs investigated (Additional file 12: Figure S6). Members of the NPF2-2 subfamily (AtNPF2.3, AtNPF2.4, AtNPF2.5, and AtNPF2.7) were preferentially expressed in roots; AtNPF4.1 and AtNPF4.5 in the NPF4 subfamily were mainly expressed in seeds; and AtNPF2.10 and AtNPF2.11 in the NPF2-1 subfamily had higher expression levels in roots, stems, leaves, and flowers. Notably, the expression patterns of homologs in both species were generally conserved. Members of NPF2-1 in B. napus and Arabidopsis were preferentially expressed in flower and seed organs, and members of NPF2-2 in these two species were preferentially expressed in roots. Given that genes with similar expression patterns may share similar functions, the 


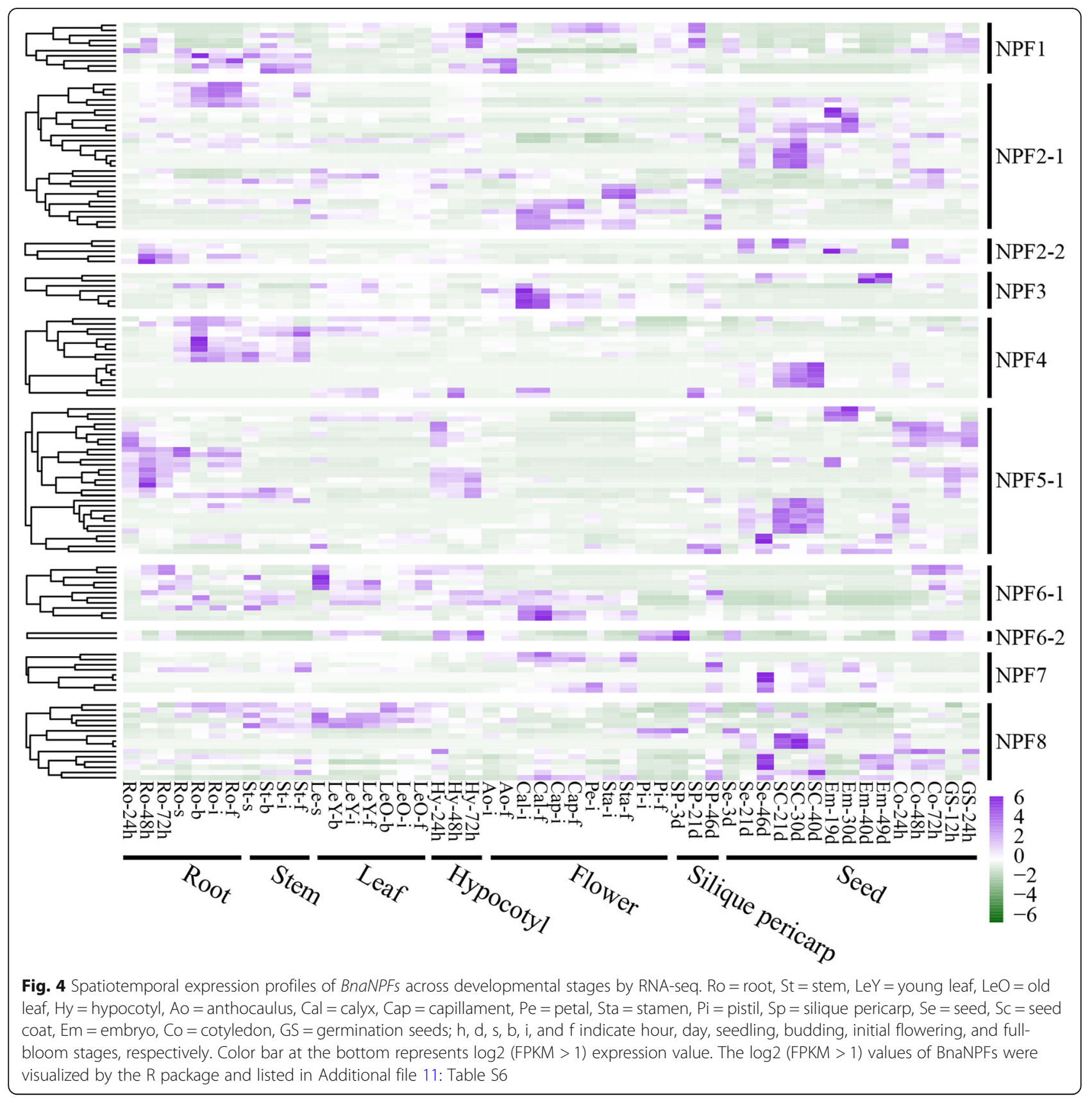

homologs may have similar/conserved functions in Arabidopsis and B. napus.

\section{Expression profiles of BnaNPFs under different hormone inductions}

As mentioned (Fig. 2), many hormone-responsive CREs were observed in the promoter regions of candidate $B n a N P F s$, suggesting possible roles for plant hormones in BnaNPF expression. Therefore, we analyzed the expression profiles of BnaNPFs under five exogenous hormone treatments (IAA, ABA, 6-BA, $\mathrm{GA}_{3}$, and $\mathrm{ACC}$ ) in
B. napus seedling roots, based on the RNA-seq data (BioProject ID: PRJNA608211).

Results showed that $32.66 \%(65 / 199)$ of the BnaNPFs were upregulated by one or more types of hormones (Fig. 5). With the exception of the NPF5-2 subfamily, which had no detectable expression level, the expression patterns of the other 10 subfamilies were induced at different levels under hormone treatments. NPF1 subfamily members were positively induced by ACC induction; $42.86 \%(3 / 7)$ of NPF3 subfamily members were upregulated by ABA and ACC treatments; and 90.91\% (10/11) of NPF6-1 subfamily members had higher expression 


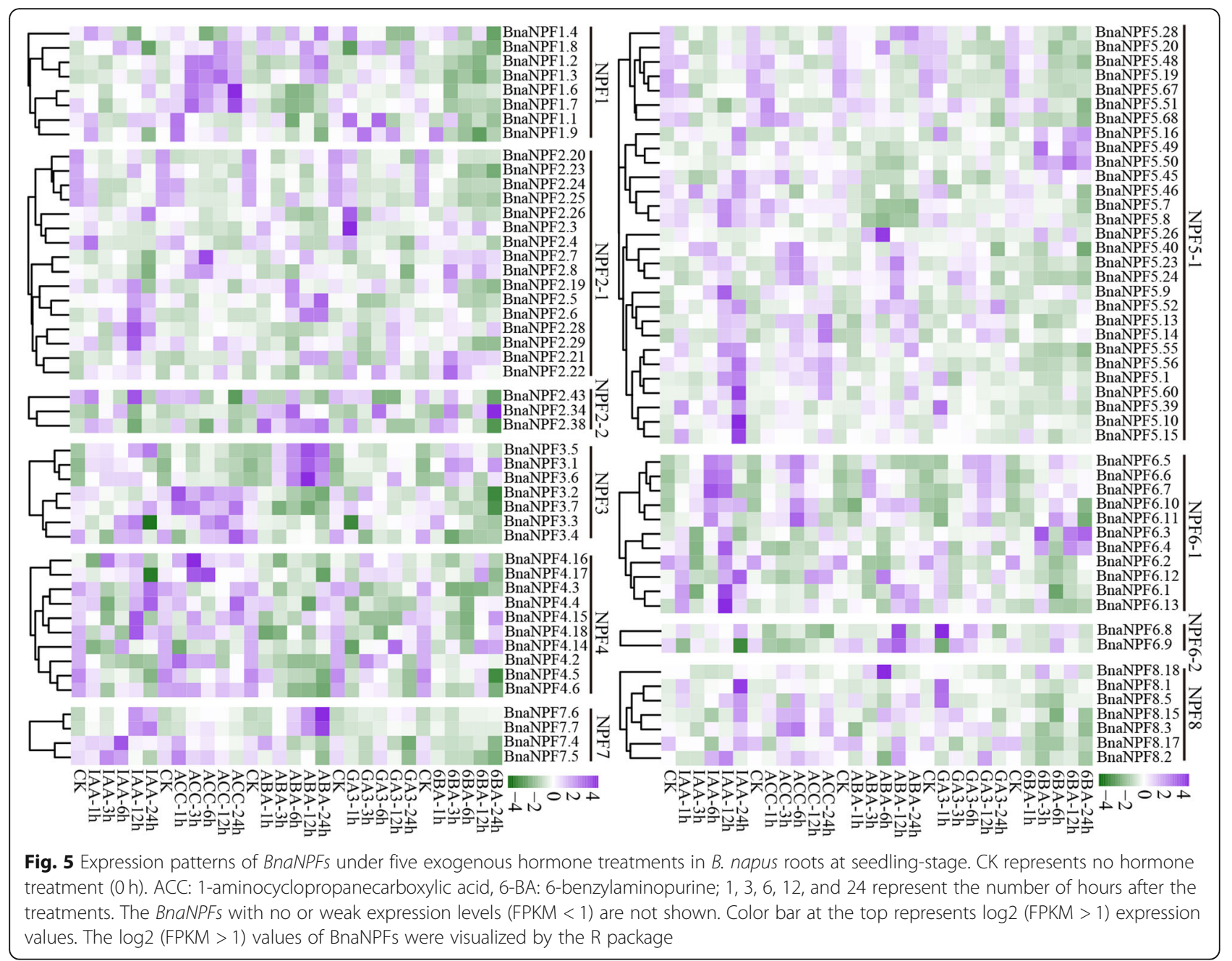

levels under the five hormone treatments. In contrast, 35.18\% (70/199) of BnaNPFs were downregulated by these five hormone treatments (Fig. 5), e.g., members of the NPF4 (BnaNPF4.2, BnaNPF4.3, BnaNPF4.4, BnaNPF4.5, BnaNPF4.6, BnaNPF4.14, BnaNPF4.15, BnaNPF4.16, BnaNPF4.17, and BnaNPF4.18) and NPF5-1 (BnaNPF5.19, BnaNPF5.20, BnaNPF5.28, BnaNPF5.48, and BnaNPF5.67) subfamilies. In general, genes in a clade or branch within a given subfamily had similar hormone-induced expression profiles, such as in the NPF2-1 (BnaNPF2.20, BnaNPF2.23, BnaNPF2.24, and BnaNPF2.25) and NPF6-1 (BnaNPF6.5, BnaNPF6.6, and BnaNPF6.7) subfamilies (Fig. 5), implying their functional conservation.

Overall, the expression of many BnaNPFs was sensitive to exogenous hormone induction, suggesting that the essential roles of this gene family in diverse plant processes may be regulated by hormone-mediated patterns.

\section{Expression of BnaNPFs in high- and low-GLS content $B$. napus varieties}

GLS is a class of important secondary metabolites found in Brassicaceae that have distinctive benefits for plant defense and human nutrition (such as inhibiting carcinogen activation) [45, 46]. Recently, several Arabidopsis NPFs, including AtNPF2.10, AtNPF2.11, and AtNPF2.9, were shown to be involved in GLS transport [20, 47]. Phylogenetic analysis showed that these proteins and their B. napus homologs (20 proteins, BnaNPF2.12BnaNPF2.30 and BnaNPF2.40) were clustered into the NPF2-1 subfamily with conserved sequence features (Fig. 1) and expression profiles (Fig. 4), implying that the B. napus homologs may have similar roles in GLS transport. To confirm the possible roles of these BnaNPFs in GLS transport, we further compared the expression profiles of 12 GLS-coding genes between low- and high-GLS content B. napus varieties, Zhongshuang 11 (ZS11; Fig. 6a and Additional file 13: Table S7) and Zhongyou 821 

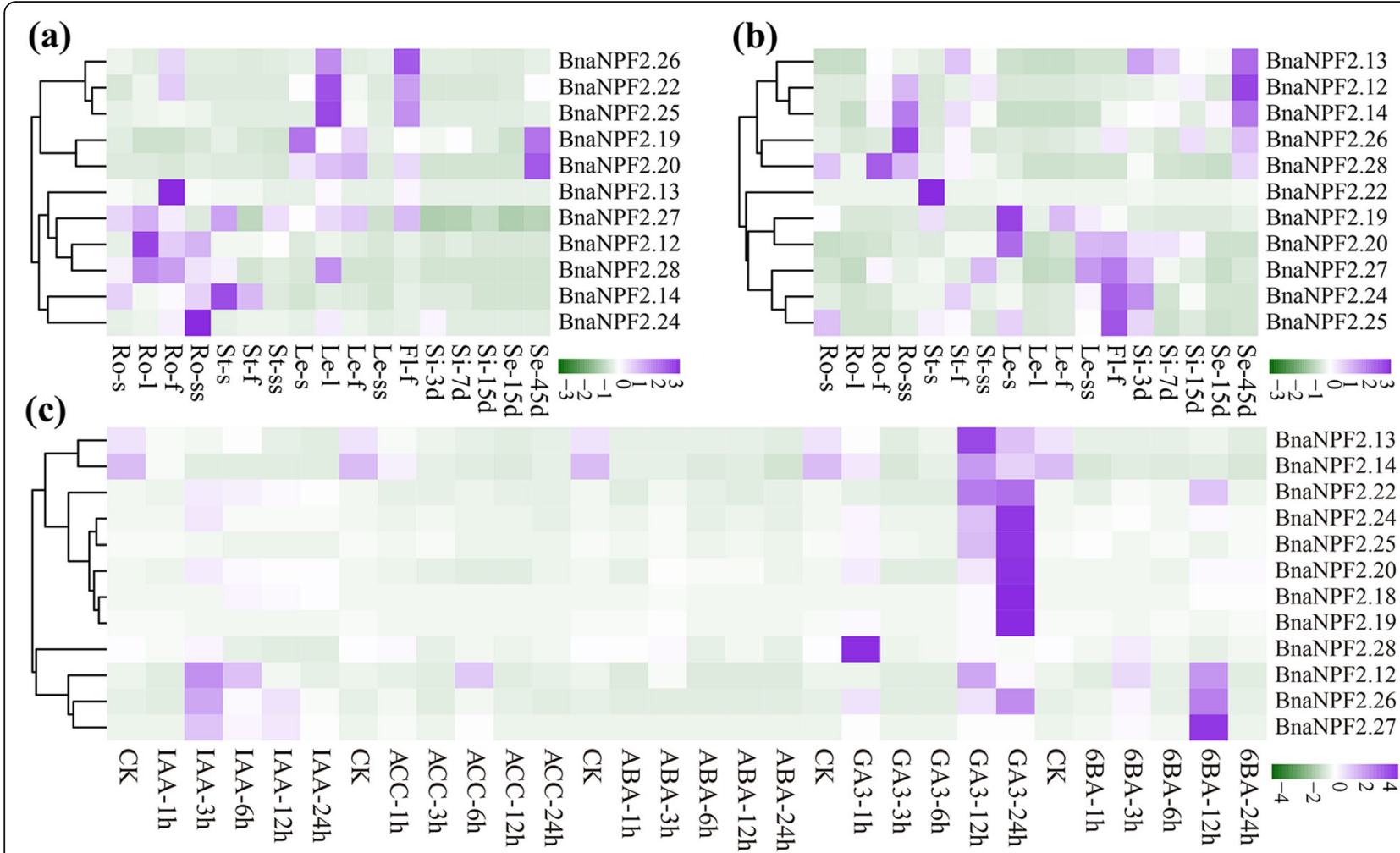

Fig. 6 Comparative expression profile analysis of 12 BnaNPFs between high- and low-glucosinolate (GLS) content B. napus varieties and under hormone treatments. a-b Expression profiles of 12 BnaNPFs in Zhongshuang 11 (ZS11; low-GLS content) and Zhongyou 821 (ZY821; high-GLS content) by qRT-PCR. Ro = root, $\mathrm{St}=$ stem, Le = leaf, $\mathrm{Si}=$ silique, $\mathrm{Se}=$ seed, $\mathrm{FI}=$ flower; $\mathrm{d}, \mathrm{s}, \mathrm{l}, \mathrm{f}$, and ss indicate day, small seedling at five-leaf stage, large seedling at eight-leaf stage, full-bloom stage, and silique stage, respectively. c Expression profiles of 12 BnaNPFs under IAA, ACC, ABA, GA, and 6-BA inductions in B. napus seedling roots. IAA: auxin; CK represents no hormone treatment $(0 \mathrm{~h})$. Color bar at the right represents log2 expression values. The log2 (expression value) of 12 BnaNPFs were visualized by the $\mathrm{R}$ package

(ZY821; Fig. 6b and Additional file 13: Table S7), using qRT-PCR [48]. Eight genes in this subfamily that have no detectable expression by RNA-Seq analysis may be pseudogenes, and thus were excluded from this analysis.

Consistent with RNA-seq results (Fig. 4), all 12 candidates were preferentially expressed in a few organs at different developmental stages; however, one gene (BnaNPF2.18) was not expressed in any of the samples investigated. Moreover, most of the other 11 candidates exhibited different expression patterns in the root, stem, leaf, flower, silique, and seed organs between the two varieties (Fig. 6a,b). For example, the three homologs of the AtNPF2.9 gene (BnaNPF2.12, BnaNPF2.13, and BnaNPF2.14) were highly expressed in seed tissues of ZY821 but had no detectable expression levels in the seed tissues of ZS11. Similarly, although the expression levels were relatively lower, two homologs of AtNPF2.11 (BnaNPF2.26 and BnaNPF2.28) were expressed in seed tissues of ZY821 but were not expressed in those of ZS11. In contrast, the homologs of AtNPF2.10 (BnaNPF2.19 and BnaNPF2.20) were highly expressed in seed tissues of ZS11 but not in those of ZY821. It was previously reported that AtNPF2.9 is the typical indole-specific
GLS transporter gene, whereas AtNPF2.11 is the transporter gene for both indole and aliphatic GLS [20,37]. Given the fact that GLS content in ZS11 seeds is significantly lower than in ZY821, our results imply that these five genes are involved in GLS transport in B. napus seed tissues, especially the three more highly expressed in ZY821 seed tissues.

We further confirmed expression patterns of the 12 candidates under five hormone treatments (IAA, ABA, 6-BA, ACC, and $\mathrm{GA}_{3}$ ) in ZS11 via qRT-PCR (Fig. 6c and Additional file 14: Table S8). Similar to the results from RNA-seq analysis (Fig. 5), the expression pattern of these candidates was divided into two major groups: the first group of genes (BnaNPF2.13, BnaNPF2.14, BnaNPF2.18, BnaNPF2.19, BnaNPF2.20, BnaNPF2.22, BnaNPF2.24, and BnaNPF2.25) was upregulated mainly by $\mathrm{GA}_{3}$ and IAA inductions, while the second group of genes (BnaNPF2.12, BnaNPF2.26, BnaNPF2.27, and BnaNPF2.28) was upregulated mainly by IAA, $\mathrm{GA}_{3}$, and 6-BA treatments. Notably, most members in the first group are homologs of AtNPF2.9 and AtNPF2.10, whereas most members in the second group are homologs of AtNPF2.11, suggesting different hormone response patterns. 
Overall, these results indicate that the homologs of AtNPF2.9, AtNPF2.10, and AtNPF2.11 may be the transporter genes for GLS in B. napus seeds, and their function may be impacted by hormone treatments.

\section{Discussion}

To date, a wide range of NPF family substrates have been characterized in plants, including nitrate/nitrite [6], di/tri-peptides [13, 14], hormones (such as IAA, ABA, GA, MeJA, etc.) [18], chloride [21, 22], potassium [23], and secondary metabolites $[20,49]$, demonstrating their diverse roles in plants. Previously, the plant NPFs were well known for their important roles in nitrate/nitrite transportation (Table 1). Accordingly, up to 10 of the 11 subfamilies of this gene family (NPF1, NPF2-1, NPF2-2, NPF3, NPF4, NPF5-1, NPF5-2, NPF6-1, NPF7, and NPF8) had been shown to be involved in nitrate transport in plants. Moreover, the majority of functionally characterized NPFs in these 10 subfamilies were lowaffinity nitrate transporters, while a few members of the NPF1 and NPF6-1 subfamilies acted as high-affinity nitrate transporters, such as AtNPF6.3 and its homolog in Medicago truncatula (MtNPF6.8) [6, 11, 13, 69-71]. NPFs were identified as important transporters for hormones as well, with eight subfamilies (NPF1, NPF2-1, NPF2-2, NPF3, NPF4, NPF5-1, NPF6-1, and NPF8) associated with hormone transportation (Fig. 1 and Table 1). Among them, members of the NPF1, NPF2-2, NPF3, NPF4, and NPF5-1 subfamilies have a relatively wider range of substrates and are commonly involved in GA, $\mathrm{ABA}$, and MeJA transports; for example, AtNPF4.1/AIT3 in the NPF4 subfamily can transport ABA, $\mathrm{GA}_{1 / 3 / 4 / 8 / 20}$, and MeJA [17, 18, 50, 55]. Members of the NPF2-1 subfamily, such as AtNPF2.10, were reported to transport two substrates (GA and MeJA) $[18,54]$. On the contrary, members of each of the NPF6-1 and NPF8 subfamilies transport only one kind of hormone: AtNPF6.3 (NRT1.1/CHL1) of the NPF6-1 subfamily is involved in IAA transport [19], while AtNPF8.1 of the NPF8 subfamily is related to MeJA transport [18]. Additionally, NPFs can transport many other substrates, including di-/tri-peptides, chloride, potassium, and secondary metabolites. For instance, AtNPF5.2/PTR3 of the NPF5-1 subfamily, and AtNPF8.1, AtNPF8.2, and AtNPF8.3 of the NPF8 subfamily showed specific dipeptide transport activity [13-16, 60]. In terms of chloride transport, AtNPF2.4 and AtNPF2.5 of the NPF2-2 subfamily mediate chloride efflux activity [21, 22]. Regarding potassium transport, AtNPF7.3 displayed $\mathrm{pH}$-dependent $\mathrm{K}^{+}$efflux activity and mediated a proton-coupled $\mathrm{H}^{+} / \mathrm{K}^{+}$ antiporter activity for $\mathrm{K}^{+}$loading into the xylem [23]. Recently, these gene family members were shown to be involved in secondary metabolite transport [20, 49]. For instance, five NPF2-1 subfamily members (AtNPF2.10, AtNPF2.11, AtNPF2.9, AtNPF2.14, and AtNPF2.13/
NRT1.7) were shown to be the key transporters for GLS $[20,37]$. Similarly, an NPF from the same subfamily in Catbarantbus roseus, CrNPF2.9, can transport monoterpene indole alkaloids [49]. Overall, NPFs have diverse substrates in plants, especially for nitrate and multiple hormone transportation.

Notably, NPFs in most subfamilies can generally transport more than one type of substrate (Table 1). For example, NPF2-1 subfamily members can transport four types of substrates: nitrate, GLS, GA, and MeJA (Fig. 1 and Table 1); in Arabidopsis, AtNPF6.3 of the NPF6-1 subfamily transports nitrate as well as auxin [19]. Moreover, many studies have found that the role of NPFs in transporting diverse substrates generally demonstrates hormone-mediated characteristics. For example, AtNPF6.3 of the NPF6-1 subfamily was highly induced by IAA treatment under low nitrogen conditions [72]. AtNPF2.4 was repressed by ABA treatment and then played a role in chlorine transport [21]. AtNPF2.10 was upregulated by MeJA treatment, which then accelerated the transport of gibberellin [54]. AtNPF3.1 was upregulated by $\mathrm{ABA}$ to promote the transport of gibberellin [55]. AtNPF5.2 was regulated by SA, MeJA, and ABA treatments against biotic and abiotic stresses [60]. In this study, many CREs involved in hormone responses, such as SA- (103/199 genes), ABA- (93/199 genes), and MeJA-responsive CRE (123/199 genes), were found in a series of BnaNPF promoters (Fig. 2), suggesting their potential hormone-inducing characteristics. Accordingly, the expression of $32.66 \%$ of the BnaNPFs (65/199 genes) were regulated by one or more types of hormone inductions (ABA, IAA, 6-BA, GA 3 , and ACC) (Fig. 5). Consistent with previous work [72], NPF6-1 subfamily proteins in B. napus (e.g., BnaNPF6.5, BnaNPF6.7, and BnaNPF6.7) were also highly induced by IAA in our study. Additionally, we revealed that the genes involved in GLS transport are induced by IAA, $\mathrm{GA}_{3}$, and 6-BA treatments (Fig. 6). Together, these results support the hypothesis that hormones have an essential role in substrate transport by NPFs.

Given that the role of NPFs in transporting many substrates is crucial for plant development and stress response, genome-wide analyses of the NPF gene family have been performed in many plant species. However, the classification of this gene family is not yet uniform. For example, this gene family was divided into 10 supergroups and 32 groups (subfamilies) based on phylogenetic analysis of 20 plant genomes [73]. In contrast, other research divided this gene family into 8 subfamilies (NPF1-NPF8) based on similar analysis in 33 plant genomes (including Physcomitrella patens and Selaginella moellendorffii) [7]. Subsequent studies generally followed the criteria of the latter division [25, 26, 74]. Recently, in apple, the NPF2 subfamily was further divided into two groups 
Table 1 Summary of the substrates of plant NPF proteins

\begin{tabular}{|c|c|c|c|c|c|c|}
\hline Species & Name & $\begin{array}{l}\text { Other } \\
\text { Name }\end{array}$ & Gene ID & Subfamily & Substrates & $\begin{array}{l}\text { Regulation by } \\
\text { hormone }\end{array}$ \\
\hline \multirow[t]{32}{*}{ Arabidopsis } & AtNPF1.1 & NRT1.12 & At3g16180 & NPF1 & $\mathrm{NO}_{3}-[10] ; \mathrm{ABA} / \mathrm{GA}_{1 / 3 / 4} / \mathrm{MeJA}[18]$ & - \\
\hline & AtNPF1.2 & NRT1.11 & At1g52190 & NPF1 & $\mathrm{NO}_{3}^{-}[10] ; \mathrm{GA}_{1 / 3 / 4} / \mathrm{MeJA}[18,50]$ & - \\
\hline & AtNPF2.3 & NAXT2 & At3g45700 & NPF2-2 & $\mathrm{GA}_{1 / 3 / 4}[18] ; \mathrm{NO}_{3}-[51]$ & - \\
\hline & AtNPF2.4 & & At3g45690 & NPF2-2 & Chloride [21]; GA $1 / 3 / 4 / \mathrm{MeJA}$ [18] & $\mathrm{ABA}$ \\
\hline & AtNPF2.5 & & At3g45680 & NPF2-2 & ABA/GA $1 / 3 / 4$ [18]; chloride [22] & - \\
\hline & AtNPF2.6 & & At3g45660 & NPF2-2 & $\mathrm{GA}_{1 / 4} / \mathrm{MeJA}[18]$ & - \\
\hline & AtNPF2.7 & NAXT1 & At3g45650 & NPF2-2 & $\mathrm{NO}_{3}-[52] ; \mathrm{GA}_{1 / 3 / 4} / \mathrm{MeJA}[18]$ & - \\
\hline & AtNPF2.9 & NRT1.9/GTR3 & At1g18880 & NPF2-1 & $\mathrm{NO}_{3}-[53] ; 4$ MTB [20] & - \\
\hline & AtNPF2.10 & GTR1 & At3g47960 & NPF2-1 & $\begin{array}{l}\mathrm{NO}_{3}{ }^{-} / 4 \mathrm{MTB} \text { [20]; 8MTO [47]; GA } 1 / 3 / 4 / \mathrm{MeJA}[18, \\
54]\end{array}$ & MeJA \\
\hline & AtNPF2.11 & $\begin{array}{l}\text { NRT1.10/ } \\
\text { GTR2 }\end{array}$ & At5g62680 & NPF2-1 & $\mathrm{NO}_{3}^{-} / 4 \mathrm{MTB}$ [20]; 8MTO [47]; $\mathrm{GA}_{3}[55]$ & - \\
\hline & AtNPF2.12 & NRT1.6 & At1g27080 & NPF2-1 & $\mathrm{NO}_{3}-[56] ; \mathrm{GA}_{1 / 3}[18]$ & - \\
\hline & AtNPF2.13 & NRT1.7 & At1g69870 & NPF2-1 & $\mathrm{NO}_{3}-[57] ; 4 \mathrm{MTB}[20] ; \mathrm{GA}_{1 / 3 / 4} / \mathrm{MeJA}[18]$ & - \\
\hline & AtNPF2.14 & & At1g69860 & NPF2-1 & 4MTB [20] & - \\
\hline & AtNPF3.1 & Nitr & At1g68570 & NPF3 & $\begin{array}{l}\mathrm{NO}_{3}{ }^{-} / \mathrm{NO}_{2}-[12] ; \mathrm{ABA} / \mathrm{GA}_{1 / 3 / 4 / 8 / 20} / \mathrm{MeJA}[18,50, \\
55\end{array}$ & $\mathrm{ABA} ; \mathrm{GA}$ \\
\hline & AtNPF4.1 & AlT3 & At3g25260 & NPF4 & ABA [39]; GA $1 / 3 / 4 / \operatorname{MeJA}[18,54] ; \mathrm{GA}_{3 / 4 / 8 / 20}[55]$ & - \\
\hline & AtNPF4.2 & AlT4 & At3g25280 & NPF4 & $\mathrm{GA}_{1 / 3}[18] ; \mathrm{ABA}[17,58]$ & - \\
\hline & AtNPF4.5 & AlT2 & At1g27040 & NPF4 & ABA $[17,18,58]$ & - \\
\hline & AtNPF4.6 & NRT1.2/AIT1 & At1g69850 & NPF4 & $\mathrm{NO}_{3}-[59] ; \mathrm{ABA}[17,18,58]$ & - \\
\hline & AtNPF5.1 & & At2g40460 & NPF5-1 & $\mathrm{ABA} / \mathrm{GA}_{1 / 3 / 4} / \mathrm{MeJA}[18]$ & - \\
\hline & AtNPF5.2 & PTR3 & At5g46050 & NPF5-1 & ABA/GA $1 / 3 / 4$ [9]; di-peptides [60] & SA; MeJA; ABA \\
\hline & AtNPF5.3 & & At5g46040 & NPF5-1 & $\mathrm{ABA}[18]$ & - \\
\hline & AtNPF5.5 & & At2g38100 & NPF5-2 & $\mathrm{NO}_{3}-[61]$ & - \\
\hline & AtNPF5.6 & & At2g37900 & NPF5-1 & $\mathrm{GA}_{1 / 4}[18]$ & - \\
\hline & AtNPF5.7 & & At3g53960 & NPF5-1 & $\mathrm{ABA} / \mathrm{GA}_{1 / 3 / 4} / \mathrm{MeJA}[18]$ & - \\
\hline & AtNPF5.10 & & At1g22540 & NPF5-1 & $\mathrm{NO}_{3}-[61]$ & - \\
\hline & AtNPF6.2 & NRT1.4 & At2g26690 & NPF6-1 & $\mathrm{NO}_{3}-[62]$ & - \\
\hline & AtNPF6.3 & NRT1.1/CHL1 & At1g12110 & NPF6-1 & $\mathrm{NO}_{3}-[6] ;$ IAA [19] & IAA \\
\hline & AtNPF7.2 & NRT1.8 & At4g21680 & NPF7 & $\mathrm{NO}_{3}-[53]$ & - \\
\hline & AtNPF7.3 & NRT1.5 & At1g32450 & NPF7 & $\mathrm{NO}_{3}-[53] ; \mathrm{K}^{+}[23]$ & - \\
\hline & AtNPF8.1 & PTR1 & At3g54140 & NPF8 & di-peptides $[13,14] ;$ MeJA [18] & - \\
\hline & AtNPF8.2 & PTR5 & At5g01180 & NPF8 & di-peptides [14] & - \\
\hline & AtNPF8.3 & PTR2/NTR1 & At2g02040 & NPF8 & di-peptides $[15,16] ;$ histidine $[63]$ & - \\
\hline \multirow[t]{4}{*}{ O.sativa } & OsNPF2.2 & OsPTR2 & Os12g44100 & NPF2-1 & $\mathrm{NO}_{3}-[64]$ & - \\
\hline & OsNPF2.4 & & Os03g48180 & NPF2-1 & $\mathrm{NO}_{3}-[65]$ & - \\
\hline & OsNPF7.2 & & Os02g47090 & NPF7 & $\mathrm{NO}_{3}-[66]$ & - \\
\hline & OsNPF8.9 & OsNRT1 & Os03g13274 & NPF8 & $\mathrm{NO}_{3}-[67]$ & - \\
\hline \multirow[t]{2}{*}{ Z. mays } & ZmNPF6.4 & & $\begin{array}{l}\text { GRMZM2G086496_ } \\
\text { P01 }\end{array}$ & NPF6-1 & chloride/ $\mathrm{NO}_{3}-[11]$ & - \\
\hline & ZmNPF6.6 & & $\begin{array}{l}\text { GRMZM2G161459- } \\
\text { P02 }\end{array}$ & NPF6-1 & $\mathrm{NO}_{3}-[11]$ & - \\
\hline C. roseus & CrNPF2.9 & & KX372303 & NPF2-1 & Alkaloid [49] & - \\
\hline V.vinifera & VVNPF3.2 & & GSVIVT01025795001 & NPF3 & $\mathrm{NO}_{3}{ }^{-} / \mathrm{NO}_{2}-[12]$ & - \\
\hline
\end{tabular}


Table 1 Summary of the substrates of plant NPF proteins (Continued)

\begin{tabular}{lllllll}
\hline Species & Name & $\begin{array}{l}\text { Other } \\
\text { Name }\end{array}$ & Gene ID & Subfamily Substrates & $\begin{array}{l}\text { Regulation by } \\
\text { hormone }\end{array}$ \\
\hline C. sativus & CsNPF3.2 & CsNitr1 & Cucsa.337560.1 & NPF3 & $\mathrm{NO}_{2}-[68]$ & - \\
M. & MtNPF1.7 & NIP/LATD & Medtr1g009200 & NPF1 & $\mathrm{NO}_{3}-[69]$ & - \\
truncatula & MtNPF6.8 & MtNRT1.3 & Medtr5g085850 & NPF6-1 & $\mathrm{NO}_{3}-[70]$ & - \\
\hline
\end{tabular}

(subfamilies) [26], implying a new classification trend. In this study, we found that three of the eight previously demonstrated subfamilies (NPF2, NPF5, and NPF6) [7] should be divided into two subfamilies with high bootstrap values: NPF2-1/NPF2-2, NPF5-1/NPF5-2, and NPF6-1/ NPF6-2, respectively (Fig. 1). To confirm this result, we further expanded our dataset to include NPFs from $O$. sativa, Populus trichocarpa, Z. mays, B. rapa, B. oleracea, and Glycine max (Additional file 2: Table S2). Phylogenetic analysis of the NPFs from these different species highly supported that of BnaNPFs (Additional file 15: Figure S7). Moreover, the gene and protein structures (Additional file 4: Figure S2, Additional file 5: Figure S3, and Additional file 6: Figure S4) and expression patterns (Figs. 4 and 5) of BnaNPFs in each subfamily supported our classification, as well. Interestingly, all the NPFs involved in secondary metabolite transport known to date belong to the NPF2-1 subfamily (Table 1). We confirmed that 267 proteins belonging to this subfamily exist in 31 angiosperms, though not in the lower plants $P$. patens and $S$. moellendorffii [7] (Additional file 16: Table S9). Given that currently known members of the NPF2-1 subfamily across different plant species, including lower plants (Table 1), are mainly involved in nitrate transport, we speculated that the secondary metabolite transport feature of this subfamily was newly evolved in a given lineage or species in angiosperms during their evolution, indicating the specific subfunctionalization trend of this gene family.

\section{Conclusions}

In this study, 199 BnaNPFs were identified in the B. napus genome and divided into 11 subfamilies having conserved gene and protein structures within each subfamily or clade. The allopolyploidy produced by its ancestors and the small-scale duplication events in B. napus acted as the primary driving forces for the massive expansion of this gene family in $B$. napus. Genes derived from B. rapa were retained after the allopolyploidy event during $B$. napus evolution. Most of the BnaNPFs were likely to be preferentially expressed in a few tissues or organs, and these expression profiles were commonly conserved in each subfamily or in each clade within a subfamily. Hormone inductions regulated the expression of many BnaNPFs. Five genes (BnaNPF2.12, BnaNPF2.13, BnaNPF2.14, BnaNPF2.26, and BnaNPF2.28) in the NPF2-1 subfamily may be involved in GLS transport in B. napus, mediated by IAA, ACC, $\mathrm{GA}_{3}$, or 6-BA.

\section{Methods}

Identification of NPF proteins in B. napus and phylogenetic analysis

The 53 AtNPFs were obtained from a previous report [20]. To identify NPFs in the B. napus genome, we performed a preliminary repeated BLASTP analysis against the proteome of $B$. napus (Darmor-bzh ecotype) in the GENOSCOPE database (http://www.genoscope.cns.fr/ brassicanapus/) [27], using AtNPFs as queries (E-value < 1.0). Preliminary sequences were analyzed by Pfam (http://pfam.xfam.org/search/sequence) [28] and SMART (http://smart.embl-heidelberg.de/smart/show_motifs.pl) to ensure that the candidates had the typical PTR2 domain [29]. The DNA, CDS, and protein sequences of candidates were obtained from the GENOSCOPE database. Predictions of molecular weight and pI of candidates were performed using ProtParam (https://web.expasy.org/ protparam/) [75]. To ensure reliability, the subcellular localization of BnaNPFs was predicted by Cell-PLoc 2.0 (http://www.csbio.sjtu.edu.cn/bioinf/Cell-PLoc-2/) [31], PProwler version 1.2 (http://bioinf.scmb.uq.edu.au:8080/ pprowler_webapp_1-2/index.jsp) [32], and WoLF PSORT (https://wolfpsort.hgc.jp/) [33] separately. Multiple sequence alignment of candidate protein sequences was performed using MAFFT version 7 online software with default parameters (https://mafft.cbrc.jp/alignment/server/ ) [34]. NJ trees were constructed with MEGA7.0 software [35] using a p-distance model and pairwise deletion, with a bootstrap analysis of 1000 replications. MEGA7.0 was also used to predict the best model for constructing the ML tree based on Bayesian information criterion (BIC) scores, then applied to construct the ML tree itself, using the bootstrap method (100 replications), JJT amino acid substitution with freqs. $(+\mathrm{F})$ model, and gamma distribution shape parameter, based on the multiple sequence alignment. Trees were visualized and edited in Evolview V3 (https://www.evolgenius.info//evolview/\#login). NPFs in the $B$. oleracea genome were identified in BRAD (http://brassicadb.org/brad/) by the same method [30]. NPF sequences in O. sativa, P. trichocarpa, Z. mays, B. rapa, and G. $\max$ were extracted from previous reports [7]. 
Sequence feature analysis and regulatory gene prediction of NPFs in B. napus

Gene structures of candidate BnaNPFs and AtNPFs were investigated by GSDS 2.0 (http://gsds.gao-lab.org/) [38] with default parameters using the DNA sequence and CDS of candidates. The TMs and other protein domains of BnaNPFs and AtNPFs were predicted by HMMER V3.1b2 (http://www.ebi.ac.uk/Tools/hmmer) [36]. Potential CREs in upstream promoter regions $(-2000 \mathrm{bp})$ of candidate BnaNPFs were predicted by PlantCARE (http://bioinformatics.psb.ugent.be/webtools/plantcare/html/) [40]. The PlantTFDB database predicted TF binding sites in promoter sequences $(-2000 \mathrm{bp})$ of candidate BnaNPFs with default parameters (http://planttfdb.gao-lab.org/) [41].

\section{Chromosomal location and collinearity synteny analysis}

The chromosome information of the 199 candidate BnaNPFs was obtained from the GENOSCOPE database. The collinear relationship of the candidate NPFs in $B$. oleracea, $B$. rapa, and $B$. napus genomes was assessed using the CoGe online software (https://genomevolution. org/CoGe/) [42] with default parameters. Duplication events of candidate NPFs were defined according to the method used in our previous report [76]. Based on cross-genome collinearity analysis, the species with the maximum orthologous blocks/most closer colinear relationships (including the NPF orthologous gene pairs) are considered the progenitors of BnaNPFs. HE, SE, and SD events were distinguished from each other based on chromosomal homology and colinear relationship (orthologous gene pairs in orthologous blocks) of the $A_{n}$ (derived from $B$. rapa) and $C_{n}$ (derived from $B$. oleracea) subgenomes and their respective progenitor genomes ( $B$. rapa and $B$. oleracea) in all possible combination pairs. The chromosome map of candidate BnaNPFs was drawn by using the MapChart software with default parameters [77].

Expression profile analysis of NPFs in Arabidopsis and B. napus The expression profile of AtNPFs (including root, stem, leaf, apex, flower, and seed) was obtained from AtGenExpress (http://weigelworld.org/resources.html) [43]. The RNA-seq data, including 50 tissues of seven B. napus variety ZS11 organs (root, stem, leaf, flower, seed, and silique) at six developmental stages (seed germination, seedling, budding, initial flowering, full-bloom, and seed maturation), were obtained from NCBI (BioProject ID PRJNA358784). Expression profiles of candidate BnaNPFs in ZS11 seedling roots under five exogenous hormone treatments (IAA, $\mathrm{GA}_{3}, 6-\mathrm{BA}, \mathrm{ABA}$, and ACC) were extracted from our RNA-seq dataset (BioProject ID: PRJNA608211). BnaNPFs with FPKM $\geq 1$ were retained, and the FPKM values of candidates were $\log 2$ transformed for visualization by the $\mathrm{R}$ package [78]. The heatmap was combined with hierarchical clustering methods of the log2-transformed RNA-Seq data [79].

\section{Plant material and hormone treatment}

The seeds of a high-GLS content $B$. napus variety (Zhongyou 821; ZY821) and a low-GLS content variety (Zhongshuang 11; ZS11) were grown in Beibei (Chongqing, China) with standard agronomic procedures to analyze the temporal and spatial expression patterns of BnaNPFs involved in GLS transport. The root (Ro-s), stem (St-s), and leaf (Le-s) tissues at the seedling stage; the root (Ro-f), stem (St-f), leaf (Le-f), and flower (Fl-f) tissues at the flowering stage; and the root (Ro-ss), stem (St-ss), leaf (Le-ss), siliques 3 days after pollination ( $\mathrm{Si}$ 3d), siliques 7 days after pollination (Si-7d), siliques 15 days after pollination ( $\mathrm{Si}-15 \mathrm{~d})$, the seed 15 days after pollination (Se-15d), and seed 45 days after pollination (Se$45 \mathrm{~d})$ at the mature stage were collected from both ZS11 and ZY821. All tissues were immediately frozen in liquid nitrogen and stored at $-80^{\circ} \mathrm{C}$ for RNA isolation.

To further analyze the expression patterns of the GLS transporter genes under five exogenous hormone inductions (ABA, IAA, GA 3 , 6-BA, and ACC), ZS11 seeds were germinated and cultivated at $25^{\circ} \mathrm{C}$ under a $16 / 8 \mathrm{~h}$ (day/ night) photoperiod in an artificial climate chamber. At the three-leaf stage, seedlings were transferred to Hoagland solution and were further cultured to the five-leaf stage. Seedlings were then treated with Hoagland's liquid medium, containing $10 \mu \mathrm{mol} / \mathrm{L}$ IAA, $50 \mu \mathrm{mol} / \mathrm{L}$ ABA, $75 \mu \mathrm{mol} / \mathrm{L}$ 6-BA, $120 \mu \mathrm{mol} / \mathrm{L} \mathrm{GA}_{3}$, and $60 \mu \mathrm{mol} / \mathrm{L} \mathrm{ACC}$. Root tissues were harvested at $0,1,3,6,12$, and $24 \mathrm{~h}$ after each treatment. All samples were quickly frozen in liquid nitrogen and then stored at $-80^{\circ} \mathrm{C}$ for RNA isolation.

\section{Expression analysis of NPFs in B. napus using qRT-PCR}

The expression profile of 12 putative GLS transporters encoding BnaNPFs of the NPF2-1 subfamily in different tissues and under five exogenous hormone inductions was analyzed via qRT-PCR, using BnaActin7 (GenBank accession no. AF024716) and BnaUBI (GenBank accession no. NC027770) as the reference genes. Primer pairs for qRT-PCR analysis were designed using Primer Premier 5 (Additional file 17: Table S10).

Total RNA was extracted from each of the samples with the EASYspin Total RNA Extraction Kit (Biomed, Beijing). The concentration and quality of total RNA for each sample were confirmed through gel electrophoresis analysis and NanoDrop 2000 spectrophotometer measurement. Potentially contaminating DNA was eliminated by DNase I (Promega, USA). The cDNA of each sample was synthesized using the M-MuLV RT kit (Takara Biotechnology, Japan). The real-time PCR analysis (qRT-PCR) was performed using the SYBR-Green PrimeScript RT-PCR Kit (Takara Biotechnology, Japan) with the CFX Connect ${ }^{\mathrm{Tm}}$ 
Real-Time System (Bio-Rad, Chongqing, China). The parameters of qRT-PCR were as follows: $95^{\circ} \mathrm{C}$ for $3 \mathrm{~min}$ (initial denaturation), followed by 40 cycles of $95^{\circ} \mathrm{C}$ for $10 \mathrm{~s}$ (denaturation) and $58^{\circ} \mathrm{C}$ for 30 s (annealing). Each PCR was validated in three independent repeat experiments. The qRT-PCR results were calculated using the $2^{-\Delta \Delta \mathrm{ct}}$ method [47]. Expression values were $\log 2$-transformed and visualized with the R package [78].

\section{Supplementary Information}

The online version contains supplementary material available at https://doi. org/10.1186/s12864-020-07274-7.

Additional file 1: Table S1. List of physical and chemical properties of candidate BnaNPF proteins.

Additional file 2: Table S2. Protein sequences and classification of NPF proteins in Arabidopsis thaliana, Oryza sativa, Populus trichocarpa, Zea mays, Brassica rapa, Glycine max, Brassica oleracea, and Brassica napus used in this study.

Additional file 3: Figure S1. Maximum likelihood (ML) tree of NPF proteins from Brassica napus and Arabidopsis. (PDF 936 kb)

Additional file 4: Figure S2. Protein structure of NPF proteins in Brassica napus and Arabidopsis. (PDF $12899 \mathrm{~kb}$ )

Additional file 5: Figure S3. The EXXEK(R) domain of NPF proteins in Brassica napus and Arabidopsis. (PDF 4401 kb)

Additional file 6: Figure S4. Gene structures of NPF genes in Brassica napus and Arabidopsis. (PDF $4090 \mathrm{~kb}$ )

Additional file 7: Table S3. List of cis-acting elements in promoter regions of BnaNPF genes.

Additional file 8: Table S4. Transcription factors with potential binding sites in promoter regions of BnaNPF genes.

Additional file 9: Figure S5. Chromosome distributions of NPF genes in Arabidopsis, Brassica rapa, and Brassica oleracea. (PDF 1556 kb)

Additional file 10: Table S5. Duplication events of NPF genes in Brassica napus, Brassica rapa, and Brassica oleracea. (XLSX $23 \mathrm{~kb}$ )

Additional file 11: Table S6. Expression profiles (FPKM value) of BnaNPF genes in 50 Brassica napus tissues at different developmental stages.

Additional file 12: Figure S6. Expression profiles of Arabidopsis NPF genes.

Additional file 13: Table S7. Expression profiles of 12 candidate BnaNPF genes in ZS11 and ZY821 by qRT-PCR.

Additional file 14: Table S8. Expression profiles of 12 candidate BnaNPF genes under hormone inductions by qRT-PCR.

Additional file 15: Figure S7. Neighbor-joining (NJ) tree of NPF proteins from Arabidopsis, Oryza sativa, Populus trichocarpa, Zea mays, Brassica rapa, Brassica oleracea, Glycine max, and Brassica napus. (PDF 2332 kb)

Additional file 16: Table S9. Distribution of the NPF2-1 subfamily members in 32 land plant species.

Additional file 17: Table S10. Primer list of the BnaNPF genes for qRTPCR analysis.

\section{Abbreviations}

TM: Transmembrane domain; GLS: Glucosinolate; CREs: Cis-acting regulatory elements; TF: Transcription factor; SE: Segmental exchange; SD: Segmental duplication; HE: Homologous exchange; TD: Tandem duplication;

ZS11: Zhongshuang 11; ZY821: Zhongyou 821; IAA: auxin; ABA: Abscisic acid; GA: Gibberellin acid; MeJA: Methyl jasmonate; 6-BA: 6-benzylaminopurine; ACC: 1-aminocyclopropanecarboxylic acid

\section{Acknowledgments}

Not applicable.

\section{Authors' contributions}

HD developed the conception of the study; JW, PFL, PCG, FR, JNL and HD drafted and revised the manuscript. PCG, FR, HD, PFL, JTZ, JY and JW contributed to data analysis. LLZ, PC, HD and PFL conceived and designed the experiments. All authors reviewed and approved the final manuscript.

\section{Funding}

This work was supported by the National Key Research and Development Program of China (2018YFD1000900).

\section{Availability of data and materials}

The data supporting the results of this study are included in manuscript and its additional files.

Ethics approval and consent to participate

Not applicable.

\section{Consent for publication}

Not applicable.

\section{Competing interests}

The authors declare that they have no competing interests.

Received: 30 June 2020 Accepted: 24 November 2020

Published online: 07 December 2020

References

1. Fei YJ, Kanai Y, Nussberger S, Ganapathy V, Leibach FH, Romero MF, Singh SK, Boron WF, Hediger MA. Expression cloning of a mammalian protoncoupled oligopeptide transporter. Nature. 1994;368:563-6. https://doi.org/10. 1038/368563a0.

2. Hauser M, Narita V, Donhardt AM, Naider F, Becker JM. Multiplicity and regulation of genes encoding peptide transporters in Saccharomyces cerevisiae. Mol Membr Biol. 2001;18:105-12.

3. Daniel H. Molecular and integrative physiology of intestinal peptide transport. Annu Rev Physiol. 2004;66:361-84. https://doi.org/10.1146/ annurev.physiol.66.032102.144149.

4. Daniel H, Spanier B, Kottra G, Weitz D. From bacteria to man: archaic proton-dependent peptide transporters at work. Physiology (Bethesda). 2006;21:93-102. https://doi.org/10.1152/physiol.00054.2005.

5. Newstead S, Drew D, Cameron AD, Postis VL, Xia X, Fowler PW, Ingram JC, Carpenter EP, Sansom MS, McPherson MJ. Crystal structure of a prokaryotic homologue of the mammalian oligopeptide-proton symporters, PepT1 and PepT2. EMBO J. 2011;30:417-26. https://doi.org/10.1038/emboj.2010.309.

6. Tsay YF, Schroeder Jl, Feldmann KA, Crawford NM. The herbicide sensitivity gene CHL1 of Arabidopsis encodes a nitrate-inducible nitrate transporter. Cell. 1993;72:705-13. https://doi.org/10.1016/0092-8674(93)90399-b.

7. Léran S, Varala K, Boyer JC, Chiurazzi M, Crawford N, Daniel-Vedele F, David L, Dickstein R, Fernandez E, Forde B. A unified nomenclature of NITRATE TRANSPORTER 1/PEPTIDE TRANSPORTER family members in plants. Trends Plant Sci. 2014;19:5-9. https://doi.org/10.1016/j.tplants.2013.08.008.

8. Liu KH, Huang CY, Tsay YF. CHL1 is a dual-affinity nitrate transporter of Arabidopsis involved in multiple phases of nitrate uptake. Plant Cell. 1999;11: 865-74. https://doi.org/10.1105/tpc.11.5.865.

9. Bouguyon E, Perrine-Walker F, Pervent M, Rochette J, Cuesta C, Benkova E, Martinière A, Bach L, Krouk G, Gojon A. Nitrate controls root development through posttranscriptional regulation of the NRT1.1/NPF6.3 transporter/ sensor. Plant Physiol. 2016;172:1237-48. https://doi.org/10.1104/pp.16.01047.

10. Hsu PK, Tsay YF. Two phloem nitrate transporters, NRT1.11 and NRT1.12, are important for redistributing xylem-borne nitrate to enhance plant growth. Plant Physiol. 2013;163:844-56. https://doi.org/10.1104/pp.113.226563.

11. Wen Z, Tyerman SD, Dechorgnat J, Ovchinnikova E, Dhugga K, Kaiser BN. Maize NPF6 proteins are homologs of Arabidopsis CHL1 that are selective for both nitrate and chloride. Plant Cell. 2017;29:2581-96. https://doi.org/10.1105/tpc.16.00724.

12. Pike S, Gao F, Kim MJ, Kim SH, Schachtman DP, Gassmann W. Members of the NPF3 transporter subfamily encode pathogen-inducible nitrate/nitrite transporters in grapevine and Arabidopsis. Plant Cell Physiol. 2014;55:162-70. https://doi.org/10.1093/pcp/pct167. 
13. Dietrich $D$, Hammes $U$, Thor $K$, Suter-Grotemeyer M, Flückiger R, Slusarenko AJ, Ward JM, Rentsch D. AtPTR1, a plasma membrane peptide transporter expressed during seed germination and in vascular tissue of Arabidopsis. Plant J. 2004;40:488-99. https://doi.org/10.1111/j.1365-313X.2004.02224.X.

14. Hammes UZ, Meier S, Dietrich D, Ward JM, Rentsch D. Functional properties of the Arabidopsis peptide transporters AtPTR1 and AtPTR5. J Biol Chem. 2010;285:39710-7. https://doi.org/10.1074/jbc.M110.141457.

15. Rentsch D, Laloi M, Rouhara I, Schmelzer E, Delrot S, Frommer WB. NTR1 encodes a high affinity oligopeptide transporter in Arabidopsis. FEBS Lett. 1995;370:264-8. https://doi.org/10.1016/0014-5793(95)00853-2.

16. Chiang CS, Stacey G, Tsay YF. Mechanisms and functional properties of two peptide transporters, AtPTR2 and fPTR2. J Biol Chem. 2004;279:30150-7. https://doi.org/10.1074/jbc.M405192200.

17. Kanno Y, Hanada A, Chiba Y, Ichikawa T, Nakazawa M, Matsui M, Koshiba T, Kamiya $Y$, Seo M. Identification of an abscisic acid transporter by functional screening using the receptor complex as a sensor. Proc Natl Acad Sci U S A. 2012;109:9653-8. https://doi.org/10.1073/pnas.1203567109.

18. Chiba Y, Shimizu T, Miyakawa S, Kanno Y, Koshiba T, Kamiya Y, Seo M. Identification of Arabidopsis NRT1/PTR FAMILY (NPF) proteins capable of transporting plant hormones. J Plant Res. 2015;128:679-86. https://doi.org/ 10.1007/s10265-015-0710-2.

19. Krouk G, Lacombe B, Bielach A. Nitrate-regulated auxin transport by NRT1.1 defines a mechanism for nutrient sensing in plants. Dev. Cell. 2010;18:92737. https://doi.org/10.1016/j.devcel.2010.05.008.

20. Nour-Eldin HH, Andersen TG, Burow M, Madsen SR, Jørgensen ME, Olsen CE, Dreyer I, Hedrich R, Geiger D, Halkier BA. NRT/PTR transporters are essential for translocation of glucosinolate defence compounds to seeds. Nature. 2012;488:531-4. https://doi.org/10.1038/nature11285.

21. Li B, Byrt C, Qiu J, Baumann U, Hrmova M, Evrard A, Johnson AA, Birnbaum KD, Mayo GM, Jha D. Identification of a Stelar-localized transport protein that facilitates root-to-shoot transfer of chloride in Arabidopsis. Plant Physiol. 2016;170:1014-29. https://doi.org/10.1104/pp.15.01163.

22. Li B, Qiu J, Jayakannan M, Xu B, Li Y, Mayo GM, Tester M, Gilliham M, Roy SJ. AtNPF2.5 modulates chloride (cl-) efflux from roots of Arabidopsis thaliana. Front. Plant Sci. 2017;7:2013. https://doi.org/10.3389/fpls.2016.02013.

23. Li H, Yu M, Du XQ, Wang ZF, Wu WH, Quintero FJ, Jin XH, Li HD, Wang Y. NRT1.5/NPF7.3 Functions as a Proton-Coupled H+/K+ Antiporter for K+ Loading into the Xylem in Arabidopsis. Plant Cell. 2017;29:2016-26. https:// doi.org/10.1105/tpc.16.00972

24. Zhao X, Huang J, Yu H, Wang L, Xie W. Genomic survey, characterization and expression profile analysis of the peptide transporter family in rice (Oryza sativa L.). BMC Plant Biol. 2010;10:92. https://doi.org/10.1186/14712229-10-92.

25. Buchner P, Hawkesford MJ. Complex phylogeny and gene expression patterns of members of the NITRATE TRANSPORTER 1/PEPTIDE TRAN SPORTER family (NPF) in wheat. J Exp Bot. 2014;65:5697-710. https://doi.org/ 10.1093/jxb/eru231.

26. Wang Q, Liu C, Dong Q, Huang D, Li C, Li P, Ma F. Genome-wide identification and analysis of apple NITRATE TRANSPORTER 1/ PEPTIDETRANSPORTER family (NPF) genes reveals MdNPF6.5 confers high capacity for nitrogen uptake under low-nitrogen conditions. Int. J. Mol. Sci. 2018;19. https://doi.org/10.3390/ijms19092761.

27. Cheng F, Liu S, Wu J, Fang L, Sun S, Liu B, Li P, Hua W, Wang X. BRAD, the genetics and genomics database for Brassica plants. BMC Plant Biol. 2011;11: 136. https://doi.org/10.1186/1471-2229-11-136.

28. Finn RD, Bateman A, Clements J, Coggill P, Eberhardt RY, Eddy SR, Heger A, Hetherington K, Holm L, Mistry J. Pfam: the protein families database. Nucleic Acids Res. 2014;42:D222-30. https://doi.org/10.1093/nar/gkt1223.

29. Letunic I, Doerks T, Bork P. SMART: recent updates, new developments and status in. Nucleic Acids Res. 2015;2015:D257-60. https://doi.org/10. 1093/nar/gku949.

30. Chou KC, Shen HB. Cell-PLoc: a package of web servers for predicting subcellular localization of proteins in various organisms. Nat Protoc. 2008;3: 153-62. https://doi.org/10.1038/nprot.2007.494

31. Bodén M, Hawkins J. Prediction of subcellular localization using sequencebiased recurrent networks. Bioinformatics. 2005;21:2279-86. https://doi.org/ 10.1093/bioinformatics/bti372.

32. Nakai $K$, Kanehisa M. Expert system for predicting protein localization sites in gram-negative bacteria. Proteins. 1991;11:95-110. https://doi.org/10.1002/ prot.340110203.
33. Wang X, Wu J, Liang J, Cheng F, Wang X. Brassica database (BRAD) version 2.0: integrating and mining Brassicaceae species genomic resources. Database (Oxford). 2015. https://doi.org/10.1093/database/bav093.

34. Katoh $\mathrm{K}$, Toh $\mathrm{H}$. Parallelization of the MAFFT multiple sequence alignment program. Bioinformatics. 2010;26:1899-900. https://doi.org/10.1093/ bioinformatics/btq224.

35. Kumar S, Stecher G, Tamura K. MEGA7: molecular evolutionary genetics analysis version 7.0 for bigger datasets. Mol. Biol. Evol. 2016;33:1870-4. https://doi.org/10.1093/molbev/msw054.

36. Potter SC, Luciani A, Eddy SR, Park Y, Lopez R, Finn RD. HMMER web server: 2018 update. Nucleic Acids Res. 2018;46:200-4. https://doi.org/10.1093/nar/gky448.

37. Jørgensen ME, Olsen CE, Geiger D, Mirza O, Halkier BA, Nour-Eldin HH. A functional EXXEK motif is essential for proton coupling and active Glucosinolate transport by NPF2.11. Plant Cell Physiol. 2015;56(12):2340-50. https://doi.org/10.1093/pcp/pcv145.

38. Hu B, Jin J, Guo AY, Zhang H, Luo J, Gao G. GSDS 2.0: an upgraded gene feature visualization server. Bioinformatics. 2015;31:1296-7. https://doi.org/ 10.1093/bioinformatics/btu817.

39. Rani V. Computational methods to dissect cis-regulatory transcriptional networks. J Biosci. 2007:32:1325-30. https:/doi.org/10.1007/s12038-007-0142-9.

40. Lescot $M$, Déhais $P$, Thijs $G$, Marchal $K$, Moreau $Y$, Van de Peer $Y$, Rouzé $P$, Rombauts S. PlantCARE, a database of plant cis-acting regulatory elements and a portal to tools for in silico analysis of promoter sequences. Nucleic Acids Res. 2002;30:325-7. https://doi.org/10.1093/nar/30.1.325.

41. Jin J, Tian F, Yang DC, Meng YQ, Kong L, Luo J, Gao G. PlantTFDB 4.0: toward a central hub for transcription factors and regulatory interactions in plants. Nucleic Acids Res. 2017;45(D1):D1040-5. https://doi.org/10.1093/nar/ gkw982.

42. Lyons E, Pedersen B, Kane J, Alam M, Ming R, Tang H, Wang X, Bowers J, Paterson A, Lisch D. Finding and comparing syntenic regions among Arabidopsis and the outgroups papaya, poplar and grape: CoGe with rosids. Plant Physiol. 2008;148:1772-81.

43. Higgins EE, Clarke WE, Howell EC, Armstrong SJ, Parkin IAP. Detecting de novo homoeologous recombination events in cultivated Brassica napus using a genome-wide SNP array. G3 (Bethesda). 2018;8:2673-83. https://doi. org/10.1534/g3.118.200118.

44. Kilian J, Whitehead D, Horak J, Wanke D, Weinl S, Batistic O, D'Angelo C, Bornberg-Bauer E, Kudla J, Harter K. The AtGenExpress global stress expression data set: protocols, evaluation and model data analysis of UV-B light, drought and cold stress responses. Plant J. 2007:50:347-63. https://doi. org/10.1111/j.1365-313X.2007.03052.x.

45. Halkier BA, Gershenzon J. Biology and biochemistry of glucosinolates. Annu Rev Plant Biol. 2006;57:303-33. https://doi.org/10.1146/annurev.arplant.57. 032905.105228.

46. Capuano E, Dekker M, Verkerk R, Oliviero T. Food as Pharma? The case of Glucosinolates. Curr Pharm Des. 2017;23:2697-721. https://doi.org/10.2174/ 1381612823666170120160832.

47. Andersen TG, Nour-Eldin HH, Fuller VL, Olsen CE, Burow M, Halkier BA. Integration of biosynthesis and long-distance transport establish organspecific glucosinolate profiles in vegetative Arabidopsis. Plant Cell. 2013;25: 3133-45. https://doi.org/10.1105/tpc.113.110890.

48. Livak KJ, Schmittgen TD. Analysis of relative gene expression data using real-time quantitative PCR and the 2(-Delta Delta C(T)) method. Methods. 2001;25:402-8. https://doi.org/10.1006/meth.2001.1262.

49. Payne RM, Xu D, Foureau E, Teto Carqueijeiro Ml, Oudin A, Bernonville TD, Novak V, Burow M, Olsen CE, Jones DM. An NPF transporter exports a central monoterpene indole alkaloid intermediate from the vacuole. Nat Plants. 2017:3:16208. https://doi.org/10.1038/nplants.2016.208.

50. David LC, Berquin P, Kanno Y, Seo M, Daniel-Vedele F, Ferrario-Méry SN. availability modulates the role of NPF3.1, a gibberellins transporter, in GAmediated phenotypes in Arabidopsis. Planta. 2016;244:1315-28. https://doi. org/10.1007/s00425-016-2588-1.

51. Taochy C, Gaillard I, Ipotesi E, Oomen R, Leonhardt N, Zimmermann S, Peltier JB, Szponarski W, Simonneau T, Sentenac H. The Arabidopsis root stele transporter NPF2.3 contributes to nitrate translocation to shoots under salt stress. Plant J. 2015;83:466-79. https://doi.org/10.1111/tpj.12901.

52. Segonzac C, Boyer JC, Ipotesi E, Szponarski W, Tillard P, Touraine B, Sommerer N, Rossignol M, Gibrat R. Nitrate efflux at the root plasma membrane: identification of an Arabidopsis excretion transporter. Plant Cell. 2007:19:3760-77. https://doi.org/10.1105/tpc.106.048173. 
53. Li JY, Fu YL, Pike SM, Bao J, Tian W, Zhang Y, Chen CZ, Zhang Y, Li HM, Huang J. The Arabidopsis nitrate transporter NRT1.8 functions in nitrate removal from the xylem sap and mediates cadmium tolerance. Plant Cell. 2010;22:1633-46. https://doi.org/10.1105/tpc.110.075242.

54. Saito H, Oikawa T, Hamamoto S, Ishimaru Y, Kanamori-Sato M, SasakiSekimoto Y, Utsumi T, Chen J, Kanno Y, Masuda S. The jasmonateresponsive GTR1 transporter is required for gibberellin-mediated stamen development in Arabidopsis. Nat Commun. 2015;6:6095. https://doi.org/10. 1038/ncomms7095.

55. Tal I, Zhang Y, Jørgensen ME, Pisanty O, Barbosa IC, Zourelidou M, Regnault T, Crocoll C, Olsen CE, Weinstain R. The Arabidopsis NPF3 protein is a GA transporter. Nat Commun. 2016;7:11486. https://doi.org/10.1038/ ncomms11486.

56. Almagro A, Lin SH, Tsay YF. Characterization of the Arabidopsis nitrate transporter NRT1.6 reveals a role of nitrate in early embryo development. Plant Cell. 2008;20:3289-99. https://doi.org/10.1105/tpc.107.056788.

57. Fan SC, Lin CS, Hsu PK, Lin SH, Tsay YF. The Arabidopsis nitrate transporter NRT1.7, expressed in phloem, is responsible for source-to-sink remobilization of nitrate. Plant Cell. 2009;21:2750-61. https://doi.org/10.1105/tpc.109.067603.

58. Léran S, Noguero M, Corratgé-Faillie C, Boursiac Y, Brachet C, Lacombe B. Functional characterization of the Arabidopsis Abscisic acid transporters NPF4.5 and NPF4.6 in Xenopus oocytes. Front. Plant Sci. 2020;11:144. https:// doi.org/10.3389/fpls.2020.00144

59. Huang NC, Liu KH, Lo HJ, Tsay YF. Cloning and functional characterization of an Arabidopsis nitrate transporter gene that encodes a constitutive component of low-affinity uptake. Plant Cell. 1999;11:1381-92. https://doi. org/10.1105/tpc.11.8.1381.

60. Karim S, Holmström KO, Mandal A, Dahl P, Hohmann S, Brader G, Palva ET, Pirhonen M. AtPTR3, a wound-induced peptide transporter needed for defence against virulent bacterial pathogens in Arabidopsis. Planta. 2007;225: 1431-45. https://doi.org/10.1007/s00425-006-0451-5.

61. Léran S, Garg B, Boursiac Y, Corratgé-Faillie C, Brachet C, Tillard P, Gojon A, Lacombe B. AtNPF5.5, a nitrate transporter affecting nitrogen accumulation in Arabidopsis embryo. Sci. Rep. 2015;5:7962. https://doi.org/10.1038/ srep07962.

62. Chiu CC, Lin CS, Hsia AP, Su RC, Lin HL, Tsay YF. Mutation of a nitrate transporter, AtNRT1:4, results in a reduced petiole nitrate content and altered leaf development. Plant Cell Physiol. 2004;45:1139-48. https://doi. org/10.1093/pcp/pch143.

63. Frommer WB, Hummel S, Rentsch D. Cloning of an Arabidopsis histidine transporting protein related to nitrate and peptide transporters. FEBS Lett. 1994:347:185-9. https://doi.org/10.1016/0014-5793(94)00533-8.

64. Li Y, Ouyang J, Wang YY, Hu R, Xia K, Duan J, Wang Y, Tsay YF, Zhang M. Disruption of the rice nitrate transporter OsNPF2.2 hinders root-to-shoot nitrate transport and vascular development. Sci. Rep. 2015;5:9635. https:// doi.org/10.1038/srep09635

65. Xia X, Fan X, Wei J, Feng H, Qu H, Xie D, Miller AJ, Xu G. Rice nitrate transporter OsNPF2.4 functions in low-affinity acquisition and long-distance transport. J Exp Bot. 2015;66:317-31. https://doi.org/10.1093/jxb/eru425.

66. Hu R, Qiu D, Chen Y, Miller AJ, Fan X, Pan X, Zhang M. Knock-down of a tonoplast localized low-affinity nitrate transporter OsNPF7.2 affects rice growth under high nitrate supply. Front. Plant Sci. 2016;7:1529. https://doi. org/10.3389/fpls.2016.01529.

67. Lin CM, Koh S, Stacey G, Yu SM, Lin TY, Tsay YF. Cloning and functional characterization of a constitutively expressed nitrate transporter gene, OsNRT1, from rice. Plant Physiol. 2000;122:379-88. https:/doi.org/10.1104/pp.122.2.379.

68. Sugiura M, Georgescu MN, Takahashi M. A nitrite transporter associated with nitrite uptake by higher plant chloroplasts. Plant Cell Physiol. 2007;48:102235. https://doi.org/10.1093/pcp/pcm073.

69. Bagchi R, Salehin M, Adeyemo OS, Salazar C, Shulaev V, Sherrier DJ, Dickstein R. Functional assessment of the Medicago truncatula NIP/LATD protein demonstrates that it is a high-affinity nitrate transporter. Plant Physiol. 2012;160:906-16. https://doi.org/10.1104/pp.112.196444.

70. Morère-Le Paven MC, Viau L, Hamon A, Vandecasteele C, Pellizzaro A, Bourdin C, Laffont C, Lapied B, Lepetit M, Frugier F. Characterization of a dual-affinity nitrate transporter MtNRT1.3 in the model legume Medicago truncatula. J Exp Bot. 2011;62:5595-605. https://doi.org/10.1093/jxb/err243.

71. Lin SH, Kuo HF, Canivenc G, Lin CS, Lepetit M, Hsu PK, Tillard P, Lin HL, Wang YY, Tsai CB. Mutation of the Arabidopsis NRT1.5 nitrate transporter causes defective root-to-shoot nitrate transport. Plant Cell. 2008;20:2514-28. https://doi.org/10.1105/tpc.108.060244.
72. Guo FQ, Wang R, Crawford NM. The Arabidopsis dual-affinity nitrate transporter gene AtNRT1.1 (CHL1) is regulated by auxin in both shoots and roots. J Exp Bot. 2002;53:835-44. https://doi.org/10.1093/jexbot/53.370.835.

73. von Wittgenstein NJ, Le CH, Hawkins BJ, Ehlting J. Evolutionary classification of ammonium, nitrate, and peptide transporters in land plants. BMC Evol Biol. 2014;14:11. https://doi.org/10.1186/1471-2148-14-11.

74. Zhang H, Li S, Shi M, Li S, Wang S, Shi L, Xu F, Ding G. Genome-wide systematic characterization of the NPF family genes and their transcriptional responses to multiple nutrient stresses in Allotetraploid rapeseed. Int J Mol Sci. 2020;21:E5947. https://doi.org/10.3390/ijms21175947.

75. Artimo P, Jonnalagedda M, Arnold K, Baratin D, Csardi G, de Castro E, Duvaud S, Flegel V, Fortier A, Gasteiger E. ExPASy: SIB bioinformatics resource portal. Nucleic Acids Res. 2012;40:W597-603. https://doi.org/10. 1093/nar/gks400.

76. Li P, Wen J, Chen P, Guo P, Ke Y, Wang M, Liu M, Tran LP, Li J, Du H. MYB superfamily in Brassica napus: evidence for hormone-mediated expression profiles, large expansion, and functions in root hair development. Biomolecules. 2020;10(6):E875. https://doi.org/10.3390/biom10060875.

77. Voorrips RE. MapChart: software for the graphical presentation of linkage maps and QTLs. J Hered. 2002;93:77-8. https://doi.org/10.1093/jhered/93.1.77.

78. Galili T, O'Callaghan A, Sidi J, Sievert C. Heatmaply: an R package for creating interactive cluster heatmaps for online publishing. Bioinformatics. 2018;34:1600-2. https://doi.org/10.1093/bioinformatics/btx657.

79. Petryszak R, Burdett T, Fiorelli B, Fonseca NA, Gonzalez-Porta M, Hastings E, Huber W, Jupp S, Keays M, Kryvych N. Expression atlas update--a database of gene and transcript expression from microarray- and sequencing-based functional genomics experiments. Nucleic Acids Res. 2014;42:D926-32. https://doi.org/10.1093/nar/gkt1270.

\section{Publisher's Note}

Springer Nature remains neutral with regard to jurisdictional claims in published maps and institutional affiliations.

Ready to submit your research? Choose BMC and benefit from:

- fast, convenient online submission

- thorough peer review by experienced researchers in your field

- rapid publication on acceptance

- support for research data, including large and complex data types

- gold Open Access which fosters wider collaboration and increased citations

- maximum visibility for your research: over $100 \mathrm{M}$ website views per year

At BMC, research is always in progress.

Learn more biomedcentral.com/submissions 